\title{
Mood Disorders in the Puerperium and the Role of the Midwife: Study on Improvement of Midwives' Knowledge About Post-Natal Depression After an Educational Intervention
}

\author{
Ana Polona Mivšek and Teja Zakšek \\ Faculty of Health Ljubljana, Midwifery Department \\ Slovenia
}

\section{Introduction}

Family, not only in terms of cohabitation of two adults, but in term of intragenerational symbiosys, is formed with the birth of a child (Musek, 1995). Pregnancy and birth are one of the major transitions in the life of a family members; they can promote family's evolution (Nastran Ule, 1993) however if they represent adaptational stress that family members are unable to cope with, can have harmful effect, resulting in the mental crisis of individuals (Zavrl, 1999); especially the mother. Being a mother nowadays is harder that ever before. Parenthood must be squeezed in the rifts between the strata of social life - policy, economy, industry, trade ect. and parenthood is considered of low value in comparison with those cathegories. Child represents some sort of private luxury. Women, often professionally engaged, therefore expect the task of motherhood in a strategic spirit - they carefully plan the pregnancy, are determined to deal with the motherhood succesfully and to return as soon as possible into the 'normal state', this is life as before the pregnancy (Kitzinger, 1994; Gatrell, 2005). As they became aware that parenthood is a life style and that child affect all aspects of their life that is going to change forever, they can be surprised, or even feel traped. This feelings, beside the newborn care that can be stressful because of repetitive and monotonous everyday activities, can provoke in women feelings of loss - loss of professional identity, previous lifestyle, autonomy ect. (Mauthner, 1999; Beck C.T., 1995a). Because of high (and sometimes unrealistic) expectations that they developed in pregnancy for themselves as mothers, they can suffer the feelings of guilt and inadequacy because they failed to become 'perfect mother' and have 'innapropriate' feelings towards the child. They must realize that the perfect mother does not exist (Kitzinger, 1994); it is just an arteficial product of the society, created by the ilusions of the media with the reminders of praised traditional role of women. Self-esteem and self-confidence are exposed to severe stress during postpartum. A lot of women pass this transition unharmed, but some of them can not cope mentally with all the changes; they can respond with feelings of dissapointment, anger, guilt or even depression. It is ironic that family, social institution, primary constructed for reproduction, is at most at strike just with the birth of the child (Welburn, 1980). 


\section{Background}

Mothers' postnatal mental illness affects all family members and Post-Natal Depression [PND] can be therefore regarded as a problem of the society. It is therefore crucial to prevent it, or at least diagnose and treat it as soon as possible. Interventions must be family centered. Midwives who care for the women postnatally can contribute a lot to the well-being of the family. To understand the concept of PND that was tested in the study, described in this chapter later on, first the literature review was done about main features of postnatal mental health disorders.

\subsection{History of postnatal mood disorders}

The first description of postnatal mental health disorders appeared in ancient times, when Hippocrates wrote about a woman who became 'unstable' after the delivery of twins (Ličina \& Radovanovič, 1995). While the doctors in ancient times presumed that lochia and milk went into the mother's head and caused mental disorders, in the Middle Ages the predominant thinking was that possession with demons caused these disorders. In $16^{\text {th }}$ century Protestantism, when everything was seen from the religious perspective, motherhood was considered to be a means of salvation from original sin (Littlewood \& McHugh, 1997) and so mental instability after labour was an expected consequence.

In the 19th century Holm stated that infection was the main cause of postnatal disturbances, Magnan emphasised hereditary factors, while Regis believed that depression arose in response to an autointoxication by an unknown substance produced by the body on its own (as cited in Brochington et al., 1990). In the 1950s psychoanalysts considered motherhood to be the mainstay of women's roles (Leathers et al., 1997) and thought depression was caused by a suppression of sexuality or inappropriate psychosexual development (Cox, 1986). A Parisian doctor, Louis Victor Marcé, was the first person to describe postnatal mood disorders, stating that emotionally stable women could be prone to episodes of instability after giving birth (Littlewood \& McHugh, 1997). However, his approach was psychiatric and it took until the 1950s for PND to be described as a non-psychotic disorder for the first time (Stewart \& Henshaw, 2002). In the 1960s, a biological basis for PND was revealed (Leathers et al., 1997). On the basis of the biological background, which supported a hormonal or hereditary cause of PND, Römer developed a theory that assumed that the endogen predisposition which birth triggers is the reason for mental disorders in the postnatal period, and Graver also sought explanations for PND in endocrine changes (as cited in Brochington et al., 1990).

In the inter-war years in the United Kingdom (UK) the Infanticide act (1932) was adopted. It provided extenuating circumstances for "women who were responsible for the death of their newly born babies (up to a one year), as they had not fully recovered from the effect of lactation and for this reason the balance of their mind was disturbed" (Littlewood \& McHugh, 1997, p. 15). Women were considered to be totally under the influence of their hormones and biology. It was not until the feminist movement that psychosocial aspects of postnatal mood disorders began to be recognised. In the 1970s and 1980s women's roles were in transition and more importance was being given to their roles as mothers (Leathers et al., 1997).

This brief history shows how the varied and controversial opinions have influenced thinking about PND and made it difficult to define the aetiology of PND. 


\subsection{Postnatal mood disorders in different cultures}

It was believed for a long time that only women from western societies suffered from PND and that postnatal mood disorders were defined by culture (DeAngelis, 1997). However, conditions with similar symptoms have also been identified in other countries (Cox, 1986). Some studies have found the same prevalence of PND in different societies (Huang \& Mathers, 2001), however, in general, European and Australian women appear to have lower levels of PND than women in the United States of America (USA). Women from Asia and South Africa have been identified as being most at risk (Affonso et al., 2000).

Culture influences the perception of childbearing. It defines the woman's own perception and desire for support (Stuchbery et al., 1998) and also the level of expressed dissatisfaction if the help provided does not match her needs. The expression of complaints is more frequent in some cultures, while in others women are taught to suppress dissatisfaction and personal problems (Hearn et al., 1998; Stuchbery et al., 1998). The support needed also varies in type - some societies perceive emotional support as helpful, while others prefer practical support. Culture also defines the support clients expect from the care-giving staff (Simkin, 1996). The culture of a society also affects its predominant view of mental illnesses, and the social stigma of postnatal mood disorders may prevent women from expressing negative or ambivalent feelings.

Many societies have definite rules about how a woman should behave in the first month after the birth of a child. These rules also define the appropriate attitude of the community towards puerperal women. Extra attention is often given to a mother by her family during the six-week period after the birth (Cox, 1986). In Japan, for example, there is a custom called "Stagaeri-Bunben « that provides the mother with practical support and marks her rite of passage to parenthood (Okano et al., 1998). It is believed that rituals lower the levels of distress and depression in the postnatal period (Stuchbery et al., 1998), but only when the 'passenger' believes in the efficacy of the rituals (Littlewood \& McHugh, 1997).

It is possible that a lack of universally accepted rituals and traditions around childbearing in western societies (Stuchbery et al., 1998) partially contributes to the phenomenon of PND. The ethic of individualism, competition, mobility, economical narrowness and the medicalization of childbirth are not supportive of new mothers (LoCicero et al., 1997). In modern society a return to normal domestic functioning is expected of women soon after their arrival home from the maternity hospital and the fact that a woman is still physically and psychologically very vulnerable at that time is not considered (Cox, 1986). The culture breeds expectations of motherhood that in current circumstances become unrealistic.

Today women miss helping hands and someone close to talk to, which in the past the extended family provided, but now, with the predominance of the nuclear family, this support has gone. Furthermore, motherhood is not as instinctive as is often suggested, but it is a highly skilled job that someone can learn only from observing and role modelling. This is hard in a modern society where breastfeeding and other activities in connection with motherhood are often closed to outsiders or hidden from the public eye. In developing countries motherhood is valued differently to western communities where being a mother is equated with low status, reinforces isolation and lacks recognition, all of which in turn provoke feelings of worthlessness in the mother (Welburn, 1980). It is not surprising that in this context, women understand motherhood through the context of loss (Mauthner, 1999; 
Beck C.T., 1995a). These conditions are not specific to the individual, but are a socially structured issue (Thurtle, 1995).

\subsection{Classification of postnatal mood disorders}

Until recently, postnatal mood disorders were not considered to be mental disorders in their own right and so did not warrant separate categorisation (Littlewood \& McHugh, 1997). This was also obvious from the International Classification of Diseases [ICD] 10 (World Health Organisation [WHO], 1992). The WHO considers postnatal mood disorders to be clinically identical to affective disorders in general and classifies them in the ICD 10 according to the syndrome, rather than aetiologically (Murray, 1996). In ICD 10 the general code for mental health disorders in the postnatal period is F53, and subtypes mark the severity and the form of the depression.

Another classification is given in the Diagnostic and Statistical Manual of mental disorders [DSM] IV (American Psychiatric Association [APA], 1994). This has a special categorisation for postnatal onset, but it still does not describe postnatal mood disorders as a separate entity (LoCicero et al., 1997; Sand Sobey, 2002; Bozoky \& Corwin, 2002). However, the codes and terms are said to be compatible with ICD 10 (Benner-Carson, 2000). Additionaly Cox (2004) claims that this classification is limited because it permits the classification of mental and behavioural disorders associated with the puerperium only if they onset within six weeks and if they cannot be classified elsewhere.

Experts have agreed that both classifications should be changed in order to correctly address the phenomenon of PND (Paykel, 2000), but first it must be agreed whether PND is even an illness in its own right. It is not clear, whether postnatal forms of mental disorders are different from those in other life periods (Pajntar, 1994). Some experts claim that PND is different from conditions that occur at other times in a woman's life (Dalton \& Herxheimer, 1997; Pitt, 1968). That is, severe PND, when compared with general conditions of severe depression, has more significant self-accusing behaviour, psychomotor agitation, suicidal tendencies, auditory hallucinations and disorientation (Dean \& Kendall, 1981).

It is known that rates of depression in the postnatal period are not significantly greater than those of depression at other times in women's lives (Hanusa et al., 2008). Thus it could be thought that a postnatal mood disorder is just a depressive state that coincidentally occurs at the time of childbearing. Some authors have observed that there is little difference between the symptoms of PND and general depression but with the symptoms appearing to be less severe in postnatal cases (Whiffen \& Gotlib, 1993).

Clinicians and researchers divide mood disorders after the childbirth into three categories (Murray, 1996):

- postnatal blues;

- PND that can range from mild to moderate or severe (Brockington, 2000) and

- puerperal psychosis (Clarke-Akalanue \& Myles, 2002).

There is still a question as to whether these are three separate conditions or a single condition with different levels of severity (Brochington, 1992). The line between postnatal severe depression with suicidal tendency and puerperal psychosis is very hard to define. 
Postnatal blues is defined as a transitory mood swing that affects approximately $66 \%$ (estimates range from 50 to 80\%) of women after the birth (Murray, 1996; Clarke-Akalanue \& Myles, 2002; Hewitt et al.,2009). The peak occurrence is around the fourth day after the birth and the unstable mood usually resolves by the tenth day (Wisner et al., 2002). Sometimes postnatal blues last only for a few hours (Boath \& Henshaw, 2001). The postnatal blues is thought to be the result of changes in a woman's hormonal balance after the birth. Initial euphoria converts to emotional lability with weepiness, lack of will, inability to concentrate, irritability (Ličina \& Radovanovič, 1995; Leathers, 1997), sadness, anxiety and confusion (Wisner et al., 2002). If it ends spontaneously within approximately ten days does not leave any consequences (Hirst \& Moutier, 2010). In cases where it lasts longer, approximately $20 \%$ of women progress to PND (Campbell et al., 1992; Sand Sobey, 2002). That is why it is important to support women who experience this minor mood disorder in order to prevent more serious conditions. Otherwise it requires no treatment and is considered to be a normal occurence (Raphael-Leff, 1991).

Puerperal or postpartum psychosis is perhaps the most serious of the postnatal mood disorders. Postpartum psychosis is the most severe and uncommon form of postnatal affective illness, with rates of $0.2 \%$ of new mothers (Jones \& Craddock , 2001) but some researchers estimate the incidence to be as high as 1-2\% (Heron et al.,2008). The clinical onset is rapid, with symptoms presenting as early as the first 48 to 72 hours postpartum, and the majority of episodes developing within the first 2 weeks after delivery and can last from six weeks to six months (Cox, 1986; CRAG, 1996). Symptoms include hallucinations, agitation (Leathers et al., 1997), hypomania or mania (Brockington, 2000), delusions, confusion (Boath \& Henshaw, 2001; Wisner et al., 2002) and suicidal tendencies with thoughts of infanticide, as the child is often included in the mother's delusional world (Raphael-Leff, 1991). Patients are out of touch with reality and have a lack of insight into their disturbed state. Puerperal psychosis is easy to recognise because it is very disturbing (Cox, 1986) with bizarre behaviour and has a sudden and dramatic onset (Buist, 1997). It often resembles manic depression (Gutteridge, 2001) where mood swings from the initial manic phase are followed by depression. If it manifests as a unipolar disorder, it is often depressive with psychotic features (Stowe \& Nemeroff, 1995). Followup studies have shown that the majority of women with puerperal psychosis meet criteria for bipolar disorder (Robling et al., 2000).

Postnatal depression is a disorder that comes somewhere in between the postnatal blues and puerperal psychosis. It is a later, more prolonged and more serious condition than the postnatal blues (McIntosh, 1993), and as it is not as sudden and obvious as puerperal psychosis, it is hard to detect. The study reported in this article refers only to this form of postnatal mood disorder, as it is not as obvious as psychosis, but is much more dangerous than the blues and is often a neglected area.

\subsection{Postnatal depression}

Postantal depression is the most common complication of childbearing and as such represents a considerable public health problem affecting women and their families. It is a later, more prolonged and more serious condition than the postnatal blues (McIntosh, 1993), and as it is not as sudden and obvious as puerperal psychosis, it is hard to detect. 


\subsubsection{Definition, onset, duration and incidence}

APA (1994) defines PND as postnatal onset of major depression, which begins 4-6 weeks postnatally and can last up to a year. It is not puerperal psychosis, which has an onset in the first postnatal week, or maternity blues, which begins 3-5 days postnatally and lasts up to 14 days (p.386). In their later definition APA (2000) states that post-natal depression is a nonpsychotic depressive illness that occurs in the first month postpartum. It is defined in DSM IV Text Revision [DSM-IV-TR] as a major depressive episode that begins within one month of delivery (APA, 2000). There is no specific definition of PND and the features are similar to a general major depressive episode, therefore the same diagnostic criteria are ussualy adopted. These are dysphoric mood, loss or decrease of interest/pleasure, accompanied with at least four biological depressive symptoms, that are present every day, most of the day, for more than two weeks (Scott, 1997; Wisner et al., 2002). Three of these symptoms should be present from the seven listed in the ICD 10 classification or four from the eight symptoms listed by DSM IV (Clement \& Elliott, 1999).

As definition of PND, also the duration and the onset of PND are not clearly defined. Researchers, differently from the official classifications, ascertain the period of onset to be between 6 and 12 weeks postnatally (Yonkers et al., 2001; Wisner et al., 2002). Most studies evaluate women for symptoms of PND during between 2 and 12 weeks postpartum. For many women, this time period may not be enough long, as depressive symptoms may appear and linger much later than 12 weeks postpartum (Hewitt \& Gilbody, 2009). Buist et al. (1999) state that routinuous screening for depression during the perinatal period is a strategy that provides an opportunity to access large numbers of women and facilitate pathways to best care. The warning signs of PND are elated feelings in late pregnancy (Littlewood \& McHugh, 1997) or in the first five days after labour, when about $10 \%$ of women experience certain kinds of 'highs' (Glover et al., 1994; Lane et al., 1997). Kesser et al. (2003) say that residual depressive symptoms are common with $50 \%$ of mothers remaining clinically depressed at 6 months postpartum and 25\% of mothers with untreated PND remaining clinically depressed even after the first year (Holden, 1991). Some researchers claim that most cases of PND spontaneously resolve in three months (Watson et al., 1984; Cox et al., 1987), some state six months (Beck C.T., 1995a; Cooper \& Murray, 1998; Yonkers et al., 2001), while other researchers think PND steadily remits only in one year (Noh, 1987; Beck C.T., 1995b). However, it is estimated that approximately $25 \%$ of mothers with PND will still be depressed one year after childbirth (Yonkers et al., 2001) if they are untreated (Cox, 1986; DeAngelis, 1997). Women who have suffered from PND are also twice as likely to experience future episodes of depression over a 5-year period (Cooper \& Murray, 1995). In severe cases, spontaneous remission is less likely (Stowe et al., 1997).

The average duration of a postpartum episode of depression (without treatment) is seven months (O'hara et al., 2000). Episode can be repeated after the discontinuation of medication, and the risk increases with the number of previous episodes. Therefore, longterm treatment for the prevention of recurrence should be considered for women who have had three or more episodes of severe depression (Wisner, 2002).

Longitudinal and epidemiological studies have yielded varying PND prevalence rates ranging from $3 \%$ to more than $28 \%$ of women in the first year following delivery Letourneau et al., 2006, Brockington, 2000). A meta-analysis of 59 studies reported an overall prevalence of PND of 13\% (O'Hara \& Swain, 1996). Beck C.T. \& Gable (2001) found 12\% prevalence of 
severe depression and $19 \%$ of minor. In their meta-analysis of 59 studies, O'Hara \& Swain (1996) found the prevalence of PND to be 13\%. Estimates of the risk of a woman having a subsequent episode of PND are also inconsistent. They range from 25\% (Wisner et al., 2001; Wisner et al., 2002) to 50-62\% (Llewellyn et al., 1997).

\subsubsection{Aetiology}

It is still not known exactly what triggers the outbreak of mental disturbances in the postnatal period. Many reasons have been suggested throughout history and are associated with the medical knowledge and trends of that period. The literature regarding the aetiology of PND is inconclusive and many researchers support the theory of a synergistic effect of a number of factors (Cox, 1986; Brockington, 2000; LoCicero et al., 2001; ClarkeAkalanue \& Myles, 2002; Skočir, 2004): the combination of hormones, genetics, environment, biochemistry, psychodynamics and behaviour (Dietch \& Bunney, 2002; Clement \& Elliott, 1999).

Beck C.T. (2002) in her meta-analysis identified 13 major risk factors for PND: marital status, marital satisfaction, social support, socio-economic status, self-esteem, antenatal depression or anxiety, history of previous depression and maternity blues, unplanned or unwanted pregnancy, life stress, child care stress and infant temperament. The quantity of these predictors calls into question their usefulness at forecasting impending development of PND (Wylie et al., 2011). In a meta-analysis of 59 studies that included in total 12810 participants, O'Hara \& Swain (1996) concluded that the prevalence rate of PND based on predictors was $13 \%$.

The onset of PND can be seen from different perspective. Among health workers, the medical model is the dominant perspective. It views PND as an illness initiated by biological factors, and that is why the preferred treatment is usually pharmacological (Beck C.T., 2002). Social factors that influence the woman's life are not considered. The woman is considered a passive person, under the influence of her hormones (Mauthner, 1998). Feminists, on the other hand, consider PND to be a social construct, developed from a loss of control and reinforced by feminine helplessness. They do not consider PND to be an illness but more a social construct (Mauthner, 1998; Beck C.T., 2002). They argue that society makes standards for motherhood that are impossible to achieve (Lazzare, 1997). In attachment theory the focus is on the woman's unmet wishes for support by her partner (Beck C.T., 2002). Pregnancy and the postnatal period are potentially stressful periods of life and partners rely on each other's support. If they are securely attached, they will react to each other's needs for support. However, if there are differences between the partners, the mother can perceive there to be a lack of support and this can lead to PND (Whiffen \& Johnson, 1998). The interpersonal theory stresses that people are the constructs of society and that personality is determined by interpersonal interactions (Beck C.T., 2002). People protect themselves from the negative reactions of others through different protective mechanisms (Sullivan, 2003). Interpersonal therapy (IPT) can therefore successfully improve interpersonal relationships by identifying the real cause of PND and alleviating it (Stuart \& O'Hara, 1995). People who support the self-labelling theory of PND see the depression as being the result of a discrepancy between a mother's feelings and society's expectations regarding motherhood. Mothers who are well socialized and are well aware of the social norms of motherhood, find their ambivalent or negative feelings towards the child inappropriate and label themselves 
as inappropriate mothers. Self-labelling is thought to be a private activity (Beck C.T., 2002) that identifies the discrepancy between real feelings and feeling rules (Thoits, 1985).

Wylie et al. (2011) say that because women are individuals, a healthcare professional would be required to have in-depth knowledge of the particular woman, before being able to make a judgement about her chances of developing PND. Of all eatiology mentioned and all studies presented, none comprehensively produces certainty of onset of PND.

\subsubsection{Symptoms}

The overall prevalence of PND is no greater in women after delivery than during pregnancy or other times during her reproductive life (Stocky \& Lynch, 2000), but still postpartum mood disorders represent the most frequent form of maternal morbidity following delivery (Letourneau et al., 2006). Included in these postpartum mood disorders, is PND a serious condition, characterized by the disabling symptoms of dysphoria, emotional lability, sleep disturbance, confusion, significant anxiety, guilt, and suicidal ideation. Frequently, further exacerbating these symptoms, women experience low self-esteem, an inability to cope, feelings of incompetence, a loss of self, and social isolation (Ritter et al., 2000). The symptoms mentioned in APA (1994, p.320) are also changes in appetite or weight, changes in sleep and psychomotor activities, decreased energy, feelings of worthlessness or guilt, difficulties in thinking, concentrating or making decisions. These symptoms are not very different from symptoms of general depression (Stowe \& Nemeroff, 1995). According to Sit \& Wisner (2009) the presentation of PND vary, but mothers with major depression typically describe a diminished pleasure in interacting with people or formerly enjoyable activities as well as feelings of low self-efficacy, rather than having depressed mood. A depressed mother is less positive, less contingent, and shows less vocal and plays interaction to her child. Resulting from the mother's depressive symptoms, the infant shows less positive affection, and less contingent behaviour (Righetti-Veltema et al., 2003). Somatic symptoms include hyperventilation, chest pains, palpitations, headache and tingling of the limbs (Brockington, 2000), flushes, nausea, dizziness (PaNDa, 2001) and panic attacks (Welburn, 1980). Bozoky \& Corwin (2002) emphasise that although fatigue is often viewed as a normal consequence of the physical adaptation to motherhood, it is a symptom that can predict depression. Some of the symptoms experienced in depression, such as weight loss, menstrual change, appetite change and low libido, may be normal in the postnatal period. Sleep disturbance is also common among new mothers, but early-morning wakening and an inability to return to sleep even when the child is asleep, are indicators of depression (Yonkers et al., 2001). Thus it is often hard to distinguish normal changes of the postnatal period from the pathology of PND. Another problem is that women often report only somatic symptoms, but above all try hard to appear less affected than they really are (Buist, 1997).

\subsubsection{Screening and diagnosing}

Still many mothers have little knowledge about depression, and may not be aware that they are depressed (Freeman et al., 2005). So screening is very important in identifying women at risk of, or with PND, because it is the first step in the pathway to treatment (Hanusa et al., 2008). It is estimated that approximately 50\% of cases of PND go undetected by health workers (Hearn et al., 1998; Beck C.T. \& Gable, 2001) and women rarely seek help on their 
own. Screening can be performed with different instruments (interviews, clinical examinations, psychological, sociological and psychiatric tests) but the most efficient tools are estimating and self-estimating scales that have been designed specifically for detecting PND. Some researchers claim that scales developed originally for general depression can be used (Lee et al., 2001), while others disagree as such scales do not consider the special characteristics of PND or rate normal physiological changes of the postnatal period as pathology (Cox, 1986).

The screening tools can be divided into those that are:

- antenatal (identifying women at risk of developing PND on the basis of risk factors, usually within the last trimester);

- $\quad$ postnatal (identifying women with symptoms of PND) and

- appropriate for use both, before and after the birth.

In most cases, women who are at risk for PND can be identified already during pregnancy so that appropriate follow-up can be initiated after delivery. However, as yet no antenatal tool has been shown to accurately predict all women who will develop PND (CRAG, 1996). This is because the predictive value of aetiological factors is not strong enough and consequently the clinical utility of any antenatal tool is of limited value (Cooper \& Murray, 1997). With a sensitive tool it would be possible to detect women who are at risk of PND in pregnancy, as the prevalence of PND in late pregnancy is similar to postnatal rates (Joseffson et al., 2001; Evans et al., 2001). Some of the commonly used antenatal screening tools are:

Predictive Index for postpartum depression: This is a 17-item self-report questionnaire designed to detect the presence of risk factors for PND. The items are concerned with emotional and physical wellbeing in pregnancy, history of mood disorders and the quality of close relationships. It is estimated that $40 \%$ of women who had a score of 35 , and $35 \%$ of women who scored 27, developed PND (Cooper et al., 1996). The scoring system is based on the mean scores of the EPDS for each risk factor. The index has a $39.8 \%$ positive predictive value (Webster et al., 2003). The sensitivity of the tool is $79 \%$ for the index and specificity is $50 \%$ (Cooper et al., 1996). The low predictive value has led some authors to suggest that it is ineffective (Cooper \& Murray, 1997).

Antepartum Questionnaire: This is a self-administered, 24-item antenatal questionnaire. Questions refer to education, social and marital status, the woman's relationship with her mother, father and partner, pregnancy and medical history, social support, early family life, self-esteem, history of PND, anxiety and sadness. The scores in each section range from zero to six. If a woman scores above 46, she needs psychiatric evaluation (Beck C.T., 2002b) because she is at risk of developing PND. The tool has a sensitivity of $82 \%$ and a specificity of $78 \%$ (Posner et al., 1997).

Beck Depression Inventory (BDI): This is a self-reported antenatal screening technique, developed by A.T. Beck et al. (1961), with 21 items (each with four options), developed from the DSM IV classification (APA, 1994). Higher total scores indicate more severe depression (Affonso, 1992). Scores for individual items range from zero to three; a total score of 10-15 points indicates mild depression, 16-19 moderate depression, 20-29 moderate to severe depression and 30-63 severe depression (Beck C.T. et al., 1992). It can be used for general and PND (Spinelli, 1997), but some researchers state that it lacks factors which are specific to 
the experience of motherhood and does not measure anxiety, which is an important symptom for PND (Littlewood \& McHugh, 1997; Beck C.T. \& Gable, 2000; Vieira, 2002). It may give false positive or false negative results as symptoms of depression may be confounded with normal conditions of the postnatal period (Cox et al., 1987; Ugarriza, 2000) and is therefore more appropriate to detect general depression. It is also not sensitive enough to pick up minor forms of depression (O'Hara et al., 1984).The BDI has acceptable reliability and validity (Beck C.T., 1995b) but does not detect mild depression, which is in fact quite common (Whiffen, 1988). It only identifies three of the 11 themes that have been found to be important in PND (contemplating death, loss of interest and guilt), but it does address some symptoms that were not found to be of major importance, such as self-hatred and hypochondriasis (Beck C.T., 1995b). The BDI has 100\% sensitivity and 99\% specificity for identifying general depression, with 0.72 positive predictive value and a negative predictive value (the percentage of all those tested as negative who are correctly identified as negative) of 1 (Lasa et al., 2000). In the case of depression in pregnancy, it has (at a cut-off score of 16 or above) $83 \%$ sensitivity and $89 \%$ specificity, a positive predictive value of 0.5 and a negative predictive value of 0.98 . As a result, some authors have recommended higher cut-off values for screening in pregnancy to exclude false positives (Holcomb et al., 1996).

Postpartal Emotional Disorders Questionnaire: Braverman \& Roux (1978) defined 19 dichotomous questions on the basis of clinical practice and current knowledge of psychopathology. After testing this questionnaire, six items (risk factors) were selected as being the most important (marital status, history of PND, unwanted pregnancy, unplanned pregnancy, marital problems and feeling of being unloved by partner) and these together had $94 \%$ sensitivity and $85 \%$ specificity. The tool is used for antenatal screening (Beck C.T., 2002).

Petrick's checklist: This is a 16-question tool based on risk factors for PND that were identified from past studies and a literature review (Petrick, 1984). It is of use in the antenatal period (Beck C.T., 1996). The questions have three possible answers (yes/no/not applicable) and the checklist can be self-administered (Petrick, 1984). Items covered include anxiety in pregnancy, support from other women, emotional support from the family or partner, unplanned pregnancy, readiness to assume the role of a mother, personal or family history of depression, recent life changes, difficulty in accepting and making changes, fear of illness, acceptance of body changes of pregnancy, relationship with mother, plan to breast-feed, and sadness or emotional swings either pre-menstrually, in connection with hormonal contraception or after previous pregnancies (Beck C.T., 2002). Sensitivity and specificity have not been reported (Beck C.T., 2002).

Boyer's checklist: Using a literature review and the research base, Boyer identified 16 dichotomous questions for antenatal screening of PND (Beck C.T., 1996). The checklist includes risk factors such as emotional swings before menstruation, antenatal anxiety, family and friends' support, feeling of being unloved by the partner, unwanted pregnancy, previous PND, other mental illness or emotional problems, lack of control, nervous or worrying character, antenatal depression, unhappy childhood, dissatisfaction with current life situation, feelings of guilt when something bad happens and financial, housing or personal problems (Beck C.T., 2002). Pregnant women with three to six affirmative answers are said to be at risk, while those with more than six positive answers are at high risk. The tool's sensitivity and specificity have not been published (Beck C.T., 1996; Beck C.T., 2002). 
Antenatal Screening Questionnaire (ASQ): The ASQ is a 10-item, self-administered, researchbased tool that is able to predict $44 \%$ of women who will develop PND (Appleby et al., 1994). Eight items are scored from zero to three and two dichotomous questions scored zero or one point. The items cover the woman's psychiatric history, antenatal worries, unwanted pregnancy, life stress and social support (Beck C.T., 2002). In a study by Appleby et al. (1994), the ASQ was able to predict $44 \%$ of women who went on to become depressed. Authors were unable to find any details about the sensitivity and specificity of the tool and this needs further investigation.

Modified Antenatal Screening Questionnaire (MASQ): The MASQ, by Stamp et al. (1996), is a self-administered, nine-item, Likert-type checklist (Beck C.T., 2002), appropriate for antenatal screening. It takes into account a woman's relationship with her partner, her problem solving style, support from relatives and friends and her psychiatric history (Beck C.T., 1998). Each item is scored from zero to two points (Beck C.T., 2002) and a score of two or more indicates a risk of PND. The instrument has $81 \%$ sensitivity and $48 \%$ specificity for mild depression, with a positive predictive value of $34 \%$ and a negative predictive value of $89 \%$. For severe depression it has $73 \%$ sensitivity and $43 \%$ specificity, with a $17 \%$ positive predictive value and $91 \%$ negative value (Stamp et al., 1996). As such it is appropriate only for screening for mild forms of PND (Beck C.T., 1998). The Crown Crisp Experiential Index (CCEI), which assess anxiety, was added to the MASQ. This tool includes 25 items. If a woman achieves 10 points on the CCEI, this is equivalent to 2 points on the MASQ and is sufficient to predict the woman to be at risk for PND (Beck C.T., 2002). The scale does not include items on childcare stress that are thought to be important in screening for PND (Beck C.T., 1998).

Despite multiple contacts with healthcare providers during the postpartum period, many women with PND are undiagnosed and untreated (Driscoll, 2006). Holden (1996) claims that postnatal detection may not be performed during the post-delivery stay in hospital, as signs do not appear until the sixth week and can be quite subtle. Therefore screening can be influenced by:

- $\quad$ the limited time of the health professional who is performing the detection;

- $\quad$ his/her willingness and qualification to use the screening tool;

- the mother's cooperation and trust (if she is afraid to be labelled as mentally ill and worries that her child will be taken away from her, she may not answer truthfully);

- the mother's ability and willingness to distinguish depressive symptoms from normal processes in the postnatal period (Richards, 1990).

To date, research in the PND has focused primarily on health professional screening methods of the detection of PND. As with antenatal tools used to detect PND there are also a number of postpartum screening tools used to detect PND. The two most frequently used tools for detection of PND in puerperium are discussed very briefly below:

Postpartum Depression Checklist (PDC): The PDC consists of a checklist of 11 symptoms of PND that were found in two qualitative studies (Beck C.T., 1992; Beck C.T., 1993) to be of importance: lack of interests, control, self-awareness, concentration and positive feelings, loneliness, uncertainty, anxiety, guilt, obsessive and suicidal thoughts. They are arranged in order of severity, starting with the least threatening, lack of concentration (Beck C.T., 1995b). If a mother is contemplating her own or her child's death, an immediate psychiatric referral 
is needed (Vieira, 2002). The screening technique should include an active dialogue between the health care professional and the mother, so that mild forms of PND can also be detected (Vieira, 2002). It is recommended for use at the discharge check at the gynaecologist, six weeks after the birth. It does not make a diagnosis but identifies a population that needs further evaluation. The interventions are derived directly from the symptoms reported (Beck C.T., 1995b). Sensitivity and specificity have not been reported for the PDC. However, false negatives may arise because some women find it difficult to confide their ambivalent feelings due to the social stigma attached to mental illness and unhappy motherhood (Vieira, 2002).

Postpartum Depression Screening Scale (PDSS): The PDSS is a 35-item, Likert-type scale, with five questions for each of seven dimensions: sleeping and eating problems, emotional lability, cognitive impairment, anxiety, guilt/shame, contemplation of harming oneself and loss of sense of self (Beck C.T. \& Gable, 2000). It is based on previous studies by Beck C.T. $(1993,1996)$. This self-report questionnaire has $94 \%$ sensitivity and $98 \%$ specificity for severe PND, and $91 \%$ sensitivity and 72\% specificity for any type of PND (i.e. both severe and mild depression) (Beck C.T. \& Gable, 2001).

There are also screening tools that can be used both antenatally and postnatally:

Postpartum Depression Predictors Inventory (PDPI): Beck C.T. (1998) developed the PDPI which can, when used antenatally, predict women who are vulnerable to PND, but can also be administered postnatally (Beck C.T. \& Gable, 2000). The tool was based on the results of a meta-analysis (Beck C.T., 1998). More recently, a revised inventory has been published which consists of 13 updated items (Beck C.T., 2001): self esteem, marital status, socioeconomic status and unplanned/unwanted pregnancy are new and added to previously identified items such as antenatal depression and past history of depression, antenatal anxiety, social support, marital satisfaction and life stress. For postnatal screening, additional items are included: childcare stress, infant temperament and maternity blues. The scale should be regularly updated with regard to risk factors that are included or possible new ones (Beck C.T., 2002). PDPI is not scored. It is a list that should be used by a health worker in conversation with the woman (Beck C.T., 1998), ideally every trimester during pregnancy and periodically until the end of the first postnatal year (Beck C.T., 2002).

Edinburgh Postpartum Depression Scale (EPDS): This is a 10-item questionnaire that can be used with mothers or to detect PND in fathers (Murray \& Cox, 1990; Clement, 1995; Littlewood \& McHugh, 1997; Clement \& Elliott, 1999). It has been specifically designed to detect PND (Beck C.T., 1992). From 21 items identified, 13 were confirmed after the pilot study and these were subsequently abbreviated into ten statements describing symptoms of depression (Cox, 1986). The statements have four possible answers, recorded on Likert-type scales, which range from zero to three (total maximum score 30). People completing the scale need to choose a response that describes their feelings in the past week (Tully et al., 1998; Vieira, 2002). Since the EPDS is a self-administered questionnaire, the questions need to be acceptable to users who may not regard themselves as unwell or in need of help (Cox et al., 1987). The tool includes symptoms such as the inability to laugh or to look forward to things with enjoyment, blaming oneself unnecessarily, feeling anxious or worried, feeling that things are too difficult to handle, difficulty sleeping because of unhappiness, feeling sad or miserable, crying, and having thoughts of harming oneself (Beck C.T., 1995b). With repeated use of the EPDS, the severity of the symptoms can be traced over time (Cox et al., 
1987). Screening at six to eight weeks postnatally and seven to nine months is recommended (Tully et al., 1998). It is said that women who score above a threshold of 12 to 13 are likely to be suffering from depressive illness, but if action is taken at the cut-off score of 9 to 10, the negative predictive value can be reduced to less than 10\% (Cox et al., 1987; Wisner et al., 2002). It is recommended that a woman with a score of 9 or higher, or those who answer the tenth question positively (suicide intention), should have a clinical interview. It has been suggested that a score of five to ten needs further evaluation after 2-4 weeks (Wisner et al., 2002). The EPDS has 95\% sensitivity (studies vary from $65-100 \%$ ) and $93 \%$ specificity (studies vary from 49-100\%) (Eberhard-Gran et al., 2001) and positive predictive values of $35.1 \%$ (Cooper \& Murray, 1997) for severe depression to 83\% overall (Cox et al., 1987), which is satisfactory when tested against the clinical psychiatric interview (Cox, 1986). The EPDS is simple to complete and does not require special psychiatric knowledge from the health care professional who interprets it. The only obstacle could be its use with women who have limited literacy, writing abilities or problems with understanding language of the tool (Cox et al., 1987). Beck C.T. (1995b) added as an obstacle the lack of an opportunity for women to describe their feelings fully. Shakespeare et al. (2003) found in their research that women prefer speaking about their feelings rather than filling out an EPDS questionnaire. Critics of the EPDS state that it does not consider symptoms such as loss of control, obsessive thoughts, loss of self, loneliness, lack of concentration (Vieira, 2002) and cognitive impairment (Powell-Kennedy et al., 2002). Of those symptoms that Beck C.T. (1992) identified to be important in PND, the EPDS includes only thoughts of harming oneself, anxiety and fear. Austin \& Lumley (2003) have criticised the EPDS because in their study only $8 \%$ of women identified as being at risk actually developed PND. This contradiction could occur because the scale excludes some risk factors that are of importance in the development of PND. Lee et al. (2000) found the EPDS to be less reliable for severe PND, but found that the results could be improved by using it in combination with the General Health Questionnaire (GHQ), which raises the positive predictive value to $78 \%$.

The characteristics of above mentioned tools suggest that the EPDS is currently the most evaluated and therefore appropriate screening tool for PND. It is also the most frequently used tool in studies on PND. New instruments are being developed all the time in order to screen more successfully for PND (for example the Brisbane mother baby scale by Webster et al. (2003) and other similar tools are currently being developed and tested). However, in a systematic review, Austin \& Lumley (2003) found that no screening instrument met the criteria for routine application in the antenatal period, because the instruments under-estimated the contribution of key domains (predicting risk factors) and therefore had poor sensitivity and positive predictive values. The lack of consensus regarding the risk factors of PND makes it almost impossible to develop an antenatal screening tool that would cover all the issues that emerged from studies on predicting PND (Skočir, 2004). It is easier to screen postnatally for the symptoms. The specificity of the symptoms in the postnatal period means that instruments developed for detecting general depression are not recommended. A screening programme may open up also other problematic areas. Women with false positive scores may become anxious or consequently develop PND. For this reason it is necessary to explain to them that the purpose of the screening instrument is not to diagnose but only to select individuals that might need additional clinical judgement and psychiatric evaluation, and that the diagnosis of PND can only be determined through a clinical examination. Screening only identifies those individuals that have certain risk characteristics, it does not determine the presence of the disease or provide a diagnosis (Tiran, 2002). 
The other problem is that although the identified antenatal risk factors are very amenable to prevention, they are not defined clearly enough and cannot provide a good basis for any predictive index for PND (Cooper \& Murray, 1997). As a result, some researchers are of the opinion that early recognition and treatment would be more effective than preventive measures (Bowe \& Watson, 2001). When PND is treated, the duration is much shorter than when it is untreated (England et al., 1994; CRAG, 1996; Barnett \& Morgan, 1996; Wisner et al., 2002). It is estimated that the duration of PND can be shortened from seven months to six weeks through treatment (CRAG, 1996; O'Hara et al., 2000).

\subsubsection{Prevention and treatment options}

The symptoms of depression or anxiety that occur amongst childbearing women are similar to those that occur at other times of life, however the choices for treatment may differ during pregnancy or when a woman is breastfeeding. The treatment should fit the individual woman's symptoms (DeAngelis, 1997; Beck C.T., 2002) and consider her preferences with regard to the severity of the illness (Wisner et al., 2002), her possible resources for support and breastfeeding (Buist, 1997). Treating PND is challenging and requires specific knowledge and expertise. Includes a variety of options.

\subsubsection{Pharmacotherapy}

There is much dabate about when to offer pharmacological treatment to women with PND. National Institute for Clinical Excellence [NICE] guidlines state that (2007) antidepressants may be considered for use in women with mild, moderate or severe PND, particularly when they are unresponsive or reluctant to participate in non-drug management programmes. Misri \& Kostaras (2002) say if the woman is at risk of suicide or infanticide, or has severe depression that does not respond to non-pharmacological treatment, then pharmacological therapy is recommended. Pharmacological treatments include use of antidepressants (Misri \& Kostaras, 2002) and hormone therapies (Lawrie et al., 2003).

There are two types of antidepressants: (1) Tricyclic Antidepressants (TCA), e.g. imipramine, nortriptyline and sertraline; and (2) Selective Serotonin Re-uptake Inhibitors (SSRI), e.g. fluoxetine, sertraline and citalopram. TCAs work by blocking neuronal uptake of noradrenaline and serotonin, and SSRIs block the reabsorption of serotonin by the presynaptic neurone (Wylie et al., 2011). When choosing an antidepressant treatment, the following should be considered:

- prior response or adverse effects of woman to this medication: concurrent medications and risk interventions;

- maternal monitoring of drug absorption - the aim is that the lowest possible dose that provides complete control of the depressive symptoms is used;

- medication that is known to result in lower infant exposure should be used;

- infant's clinical status and drug concentrations should be regularly assessed;

- $\quad$ the mother should be advised to time her breast-feeding to when the medication is at its lowest levels in the breast milk (Misri \& Kostaras, 2002, p. 908).

The risks, benefits and side effects (for the mother and the infant) must be carefully reviewed when making the decision about medication (Powell-Kennedy et al., 2002) and a careful follow-up and evaluation of benefits must be undertaken (Brockington, 2000). 
Special care must be paid in pregnancy, as infant exposure to medication is greater through placental passage than through breast milk postnatally. All psychotropic medications are found in breast milk and are passed to the nursing infant, which is why potential side effects of an infant's exposure must be weighed against the effects of untreated depression (Misri \& Kostaras, 2002). In pregnancy there is a risk of teratogenesis, while postnatally neonatal toxicity or the impact on neurodevelopment can be a risk. Usually medications are used only when a clear diagnosis has been made and there are no alternative solutions. It has been recommended that the lowest effective dose of the most established drug must be used for the shortest period (Schottish Intercollegiate Group Network [SIGN], 2002). However, some experts claim that in order to prevent a recurrence of the illness, treatment should continue for 9-12 months after the remission of symptoms (Stowe \& Nemeroff, 1995). Wisner et al. (2002) recommend starting with half the dose for the first four days after childbirth, as women are more sensitive at that time and side effects might be more likely. The dose should then be gradually increased until remission. If the woman responds to the initial dose, lasting six to eight weeks, treatment with the same dose should be continued for at least six months until full remission. If there is no improvement in the first six weeks, reevaluation of the medication must be carried out. This kind of treatment is also indicated to prevent a recurrence of PND in women with a history of depression (Wisner et al., 2002). It is important to reduce or discontinue the dose 2-4 weeks before the expected date of delivery, with recommencement after the birth, to prevent perinatal toxic symptoms and withdrawal syndrome (SIGN, 2002).

Hormonal therapy Already in 1971, Dalton has suggested that PND could be caused by having difficulty adjusting to the marked changes in hormone levels form late pregnancy to the early puerperium. Low progesterone levels after the birth were often attributed responsibility for causing PND (Nott et al., 1976), with this being the main rationale for implementing hormone treatment (Dennis et al., 1999). Dennis et al. (2009) Cochrane review of oestrogens and progestins for inhibiting and remedying PND, includes one perinatal trial by Lawrie et al. (1998), which reported a significant negative effect of progesteron on PND scores. As a consequence, progestogens (e.g. norethisterone), used to prevent PND, are now contraindicated (Wylie et al., 2011). Synthetic progesterons have adverse effects, and their use is associated with an increased risk of PND (Lawrie et al., 2003; Karuppaswamy \& Vlies, 2003). Transdermal 17-ßestradiol is useful in chronic PND (Cooper \& Murray, 1998) and is of modest value in the treatment of the late stages of severe PND (Lawrie et al., 2003, NICE 2007). Significant improvements have been noticed in the first month of treatment (Gregorie et al., 1996). Hormonal medications have not been validated yet for the prevention of recurrent PND (Boath \& Henshaw, 2001; Lawrie et al., 2003).

\subsubsection{Psychotherapeutic methods}

In depression with mild to moderate symptoms, non-pharmacological treatment is proposed (Misri \& Kostaras, 2002), but to be effective the mother must live within a supportive environment (Pinkofsky, 2000). Family involvement, such as marital therapy, has beneficial effects for all family members (Buist, 1997). However, PND which occurs in the context of a "continuum of psychiatric disturbance may be less likely to respond to these interventions « (Holden et al., 1989, p. 225). Psychotherapy can also be offered by health care providers in the primary sector, but these health care providers need to be educated for this approach (Holden et al., 1989; WHO, 1991; Yonkers et al., 2001). Because many women 
decline pharmacological treatments, these interventions are often the first line treatment (Austin, 2003). A further advantage of counselling is that it focuses on the problems behind PND and not just on easing the present symptoms (Welburn, 1980). While some experts believe that these therapies are unhelpful in the long term, they admit that there is an improvement in maternal mood right after the application (Cooper et al., 2003).

Interpersonal therapy (IPT) attempts to modify women's relationships or expectations about them. The women's expectations about motherhood and partners' support are discussed during counselling sessions and the therapy focuses on an identified problem area (Boath \& Henshaw, 2001). The mother gains a feeling of competence and control through different methods such as psychoeducation, which is a strategy to reduce risk factors associated with the development of PND (Benner-Carson, 2000), role-playing and communication analysis (Beck C.T., 2002). Relief is achieved through discussing feelings, which raises self-esteem in coping with the problems (Dietch \& Bunney, 2002). IPT is the only psychotherapy that has been shown to be effective in treating PND both before and after birth (Spinelli, 1997; Zlotnick et al., 2001). It is a good alternative to medication in pregnancy (Spinelli, 1997), even in more severe cases (Boath \& Henshaw, 2001), and at the same time it promotes more realistic expectations about motherhood (Dietch \& Bunney, 2002). It has been recommended also as a preventive measure for women at risk of PND (Zlotnick et al., 2001).

Cognitive behavioural therapy (CBT) aims to change negative thoughts that are a product of biased perception and to lift depression (Littlewood \& McHugh, 1997). First the negative thoughts must be identified and then the process of alteration begins (Cox, 1986). With successful accomplishment of given tasks, the woman achieves self-esteem and sharpens her problem solving skills (Dietch \& Bunney, 2002). It is indicated for mild to moderate forms of PND (SIGN, 2002; Meager \& Milgrom, 1996). NICE (2007) recommends 4-6 sessions of CBT or IPT for pregnant women with symptoms of depression and/or anxiety who do not meet diagnostic criteria, but symptoms interfere with social functioning. Talking therapies such as Non-directive counselling and CBT, without concurrent use of antidepressants, are both methods of treating PND (Wiley et al., 2011).

Non-directive counselling is a less intensive form of psychotherapy. The art of efficient counselling is not to give advice (Welburn, 1980). The environment should be empathic but non-interfering, close but not intimate (Cox, 1986). Therapeutic listening and extra support are said to be helpful in the treatment of depression or can be an adjunctive therapy to pharmacological treatment (Holden et al., 1989). Non-directive counselling has been shown to be as effective as antidepressant treatment for mild to moderate forms of PND, although the effects of treatment are quicker with medication (Chilvers et al., 2001). Some researchers have found non-directive counselling to be more efficient than CBT (Boath \& Henshaw, 2001). The key elements of counselling are:

- support and reassurance;

- $\quad$ education and practical advice in relation to parenting;

- open discussion about the effects of depression;

- advice on extra rest and relaxation (McCarthy, 1998).

Debriefing can be a form of therapeutic counselling. During the process, the mother integrates her childbirth experience into her life (Beck, C.T., 2002). An emotional »catharsis« that can be achieved by encouraging the woman to recollect her birth, can alleviate birth 
trauma, which could be a possible reason for post-traumatic stress disorder (Littlewood \& McHugh, 1997) and consequently for PND. It is believed to be most effective if conducted 24 to 48 hours after the traumatic experience (Littlewood \& McHugh, 1997). According to some authors, listening, support, understanding and explanation are helpful also after the nontraumatic birth, and Lavender \& Walkinshaw (1998) recommend it as a routine procedure in postnatal maternity units. However, other researchers have found it to be unsuccessful in preventing and treating PND (Small et al., 2000; Bick, 2003; Priest et al., 2003).

Listening visits are also a form of talk therapy and may prevent PND if regularly performed in pregnancy (Clement, 1995). They lessen the mother's feelings of isolation (Gutteridge, 2001).

Self help and support groups may include peer-based meetings or telephone support from women who are past sufferers of PND. They may be helpful in easing depressive symptoms, and their support has been found to be acceptable to new mothers (Dennis, 2003). Support group meetings can be beneficial, particularly if childcare is provided during the meeting, so that mothers can focus on their own needs. Open discussion can reduce the stigma associated with PND (Mauthner, 1999), as well as the isolation, and at the same time provide an opportunity for knowledge to be disseminated. Cox (1986) found that self-help groups were more effective in reducing PND symptoms when they were facilitated by a health professional. The fact that all participants in the group have a similar experience provides them with feelings of confidence, honesty, freedom and trust, which are the necessary ingredients of a psychotherapeutic relationship (Gutteridge, 2001). These groups may help to raise self-esteem, which is, as previously said, an important factor in the development and persistence of PND (SIGN, 2002). However, some researchers have reported finding no improvement in PND after group interventions (Morgan et al., 1997).

Other psychological aspects of the puerperium, such as stress, should also be assessed and treated through conversation. With support, interventions directed towards women's chronic stressors could raise their self-esteem, which in turn decreases their depressive symptoms (Hall et al., 1996).

\subsubsection{Other methods of treatment}

Complementary methods are nowadays more and more popular method of treatment of postnatal mood disorders. Partner involvement studied Misri et al. (2000), who determined the impact of a supportive partner on PND scores. This trial showed the value of including the partner in psychotherapy sessions. Women whose partners had participated in psychotherapy sessions had lower EPDS scores at the final assessment which occurred 10 weeks after the first session than those whose partners had not participated (8.6\% vs $14.7 \%)$. St. John's wort is said to be an effective treatment for mild to moderate depressive symptoms and it is said to be as effective as TCAs but with fewer side effects (SIGN, 2002). However, there is no research evidence regarding its safety which is why some experts suggest it should not be used in the childbearing period (Goldman \& Koren, 2003b). Hypnosis has been indicated in the treatment of insomnia, as one of the symptoms of PND (Pajntar, 1994). Acupuncture has also been used in the treatment of PND (Schnyer et al., 2003), however, there is little evidence to support its effectiveness. Massage therapy has been found to be effective in treating the anxiety symptoms of depression (Boath \& Henshaw, 2001). Imagery, art and music therapy can be used as adjuncts to other treatments (Boath \& Henshaw, 2001). Bright light therapy has been shown to be effective in treating PND in $49 \%$ of cases in a study 
by Oren et al. (2002). One hour of diffuse white-fluorescent light morning sessions eased symptoms of depression and had no adverse effects (Corral et al., 2000; Oren et al., 2002). Kangaroo (skin to skin) therapy was found to be an effective treatment for PND and also a prophylactic measure against PND (Dombrowski et al., 2001). Physical activity is said by some authors to have good effects on postnatal depressive symptoms (Powell-Kennedy et al., 2002; Armstrong \& Edwards, 2003) because of the effect of raised endorphines. Some researchers advocate that women with PND should exercise regularly as part of their treatment (Sampselle et al., 1999).

Electro convulsive therapy (ECT), a method of passing limited electric shocks through the brain, is believed by some to be a safe treatment option for severe types of depression where there is a danger of suicide (Misri \& Kostaras, 2002). However, it is generally reserved for women with persistent PND and women who do not respond to psychotherapy or to pharmacotherapeutics (Dietch \& Bunney, 2002; Bott, 1999). The major side effect is memory loss (Welburn, 1980). ECT is performed in the hospital as the severe forms of postnatal mood disorders need hospitalisation.

A combination of treatment methods is said to be the most effective intervention (Boath \& Henshaw, 2001). It is not only the immediate initiation of the intervention that is successful, but the intervention also needs to be specifically matched to the individual depressive symptomatology of a mother (Beck C.T., 2002).

\subsubsection{Place of treatment}

It is stated that in $75 \%$ of cases, the treatment of PND could be managed within primary care (Yonkers et al, 2001). When hospital admission is necessary, the mother and the child should not be separated, but the safety of the child must be assured. Where hospital treatment is required, it is preferable that women are treated in out-patient clinics or mother-baby units (Aiken, 2000), which were first suggested by Thomas Main in 1948 (Buist, 1997). The majority of women with severe depression and psychosis need hospitalisation and in such cases these units are useful because the mother and child stay together and can improve their relationship.

For some women, admission to hospital may cause problems (single parents for example), which is why day-clinics (Littlewood \& McHugh, 1997) or units for admission of the whole family have begun to be established (Barnett \& Morgan, 1996). The mother can care for the child with the support of health workers who provide her with knowledge and raise her self-esteem. Besides that, mothers are observed if there is a risk of infanticide (Cox, 1986). However, the responsibility for the child must be clearly defined (SIGN, 2002) so that the role of the mother is not taken away by the nurses and midwives.

Mother-baby units are said to be more successful in the treatment of PND than primary care as they are specifically designed for this group of women. Shorter duration of hospitalisation, lower relapse rate and enhanced mother's self-confidence were observed in the study by Boath \& Henshaw (2001). Available treatment otherwise depends on the nature and capacity of the clinic and the consistent availability of the nurse is of great value (Barnett \& Morgan, 1996).

Mother-baby units are a more costly option than primary care, because more staff and space are needed. Every mother needs a nurse to take care of her and her baby in a private room, 
otherwise the dangers of infection and violence arise. It is absolutely necessary for the staff to have appropriate knowledge of mental health and childcare issues (Barnett \& Morgan, 1996).

\subsubsection{The effects of mother's postnatal mood disorder on other family members}

PND affects the quality of life of mothers, has negative consequences for the emotional, behavioral, and cognitive functioning of their infants, and threatens the healthy functioning of the entire family (Sobey, 2002). It is therefore vital to assess what thoughts mother has been having and if she is concerned for herself. Family and/or partners may not know how to respond to these feelings and thoughts.The areas of risk that need to be assessed should include:

- $\quad$ suicide - thoughts, details and plans to take her own life

- $\quad$ self harm - behaviour that puts herself at risk physically (self mutilation) or the use of alcohol or drugs as a form of self medication, eg binging;

- harm baby - this may be due to neglect and difficulty caring for the baby, physical abuse as a result of the mother's inability to cope or emotional harm due to limited bonding and attachment.; infanticide is a rare but devastating outcome of PND;

- mental health risks - the woman may not be acknowledging the degree of severity of her symptoms and therefore not seeking or accepting treatment, she may be deteriorating rapidly.; her well-being can be put at increased risk (PaNDa, 2011).

Also Hagen (1999) says mothers with PND commonly have thoughts of harming themselves or their children. He claims these women exhibit fewer positive emotions and more negative emotions towards their children, are less responsive and less sensitive to infant cues, have a less successful maternal role attainment, and have consequently infants, who are less securely attached (Hagen, 1999). Beck C.T. (2002) writes that evidences show that this mood disorder not only has adverse effects on maternal-infant interaction during the first year of age, but may also have long-term effects on children over the age of one year. The mother's ongoing depression can cause harmful effects also for siblings and can contribute to emotional, behavioral, cognitive, and interpersonal problems later in life (Miller, 2002).

PND also has an effect on the couple's relationship. Living with a woman experiencing PND is difficult. Partners need a lot of support too and are known to be at risk of developing depression themselves. They often feel confused, lost and helpless (PaNDa, 2011). They can be the target of their partner's distress and irritability as she attempts to make sense of what is happening to her. There is an increase in marital discord and conflict, and men may become depressed when their wives or partners have PND (Burke, 2003).

\subsection{The role of midwives in the prevention, detection and treatment of postnatal mood disorders}

The literature suggests that $75 \%$ of cases of PND could be managed in the primary level of health care (Mc Carthy, 1998) and that midwives and nurses are capable of preventing, detecting and treating PND. Many studies have described midwives and nurses as having a pivotal role in the prevention, education, early recognition and support or treatment of women that suffer from PND (Leonard, 1998; Holden, 1996; Taylor, 1997; Wood et al., 1997; Gutteridge, 2001; Stewart \& Henshaw, 2002). Lepper et al. (1994) claim that health workers 
can play an important role in fostering maternal mental and emotional health in pregnancy and the postnatal period. It is the provision of psychological care where midwives or other primary care providers are said to be of the most assistance (Powell-Kennedy et al., 2002). Trustful relationship is crucial if we want woman to reveal ambivalent or even negative feelings about the pregnancy, her baby and own mental health. Such relationship can be built only through time and therefore the continuity of care is very important. New models of midwifery care that enable continuity and individual care during pregnancy, labour and postpartum are appropriate. With continuous care, PND is early detected and diagnosed, woman is referred to proper professionals and therefore treatment results are better (Marks et al., 2003).

\subsubsection{Pregnancy}

Depression in pregnancy is as common as depression in puerperium, therefore a lot of interventions can be used already antenatally (Lee \& Chung, 2007; Watson et al., 1984; Dennis \& Creedy, 2004; Evans et al., 2001). Researchers have been testing different preventive measures in order to estimate their efficacy. One successful prevention procedure was found to be general social support - wide social netwwork (Elliott, 1989), especially when targeted at women at risk of PND (Zlotnick et al., 2001; Elliott et al., 2002). Eden (1989) found that it was helpful for a woman to have someone to talk to and to have continuity of carer.

Because history of previous depression is an important risk factor for PND, it is important that midwives discuss also mental health issues with pregnant woman (Altschuler et al., 2001; Nonacs \& Cohen, 2002) during their antenatal examinations. Therefore it is important for midwives to have knowledge about the risk factors and symptoms of depression and to have protocols and referral systems for depressed woman that enable succesful management, such as Protokol, presented in Figure 1 (SIGN, 2002; Multidisciplinary working group for Grampian, 2001).

As shown in Figure 1 midwives can detect for PND, using interactive conversation or consultations (for example listening visits) (Holden, 1996; Welburn, 1980; Elliot et al., 2007; Jardri et al., 2010). They can also perform routinous detection in third trimester of pregnancy with screening tools like EPDS (Clement, 1995). However midwives need knowledge and skills to perform such therapeutic interventions (Taylor, 1997).

Although some authors claim that discussion about PND in pregnancy might predispose women to PND (Combes \& Sconveld, 1992; Bowe \& Watson, 2001; Austin, 2003b; Bick, 2003), it could be argued that the first possible action taken in pregnancy should be education about PND, as first time mothers have no experience about how they are likely to feel after the birth (Brockington, 2000; Shu-Shya \& Yu-Ying, 2003). Dietch \& Bunney (2002, p.144) suggest that: »Health care providers need to be proactive in educating women about their risks for depression, making them aware of symptoms«. Leaflets about the symptoms of PND and the different forms of postnatal mood disorders can be developed and distributed by antenatal health care providers (Brockington, 2000). Beck C.T. (2002) indicates that this can dispel unrealistic myths about motherhood that set women up to label themselves as failures as mothers, since mothers often have unrealistic expectations about labour and life in postnatal period (Renkert \& Beam, 2001; Mivšek, 2007; Hillan, 1992). 


\begin{tabular}{|c|c|}
\hline TIME & ACTIVITY \\
\hline ANTENATAL PERIOD & $\begin{array}{ll}\text { - } & \text { Screening about risk factors } \\
\text { - } & \text { Counseling regarding and management } \\
\text { of risk factors } \\
\text { - } \quad \text { Informations in antenatal classes }\end{array}$ \\
\hline POSTNATAL PERIOD & $\begin{array}{l}\text { Screening (EPDS)* } \\
\text { Interventions on the basis of EPDS scores }\end{array}$ \\
\hline ADDITIONAL INTERVENTIONS & $\begin{array}{ll}\text { - } & \text { EPDS screening in pregnancy } \\
\text { - } & \text { Listening visits in pregnancy } \\
\text { - } & \text { Debriefing postnataly } \\
\text { - } & \text { Midwifery-led practice } \\
- & \ldots\end{array}$ \\
\hline $\begin{array}{l}\text { * } \\
\text { - } \quad \text { Third trimester of pregnancy } \\
\text { - } \quad 6 \text { - } 8 \text { weeks postpartum } \\
\end{array}$ & $\begin{array}{l}\text { EPDS Results: } \\
\text { - } 9-13 \text { scores (reassessment after } 2 \text { weeks, } \\
\text { referral to support group) } \\
14-19 \text { scores (home visits, support, } \\
\text { referral to therapist, GP notification, } \\
\text { reassessment after } 2 \text { weeks) } \\
20 \text { or more scores (support, referral to } \\
\text { psychiatrist, GP notification, regular } \\
\text { reassessment with EPDS) }\end{array}$ \\
\hline
\end{tabular}

Fig. 1. Protocol of activities and referrals that midwives can perform regarding pre- and post- nataly according to results of EPDS screening (adapted from SIGN, 2002 and Multidisciplinary working group for Grampian, 2001).

Welburn (1980) has noted that there is often a lack of discussion in antenatal classes about the feelings and emotions of pregnancy and the postnatal period, and this could be improved by the midwives who run these lessons. In particular, midwives could be of great help in fostering effective coping skills for new mothers and facilitating their adjustment to motherhood, according to McQueen \& Mander (2003); among others also with practical skills about newborn care that would raise parents' self-confidence. It is therefore very important that competent health professionals conduct antenatal classes (Nolan, 1997; Svensson et al., 2009). It is also useful that antenatal classes continue postpartally as postpartum support groups to offer woman continuous support with concrete problems (Pairman et al., 2006).

\subsubsection{Labour}

Maternal and neonatal morbidity and mortality are often considered very powerful indicators of the quality of intrapartum care. Women's satisfaction with the experience and her feelings are often neglected (Oakley, 1993). Labour is exhausting, painful and potentially a frightening experience for women. A bad birth experience can be directly connected with PND (Welburn, 1980; Webster et al., 2003). As a consequence, midwives are in a position to indirectly prevent PND by offering adequate support, such as emotional support, comfort measures, advocacy, supporting the partner and information or advice (Hodnett, 1996). 
Nicolson (1998) has pointed out that it is dangerous when midwives, in their eagerness to deliver a healthy child, forget the mother. During the process of labour the mother is supposed to be an active participant in making decisions. The concepts of choice, control and active participation are closely linked with the satisfaction with the birth (Green \& Murray, 1994; Slade et al., 1993; Waldenström et al., 2000; Berg et al., 1996). Factors that affect the feeling of control are: continuity of care, informations about the labouring process and feeling of cooperation (Green \& Murray, 1994; Slade et al., 1993; Waldenström et al., 2000; Waldenström, 1999; Berg et al., 1996; Brown \& Lumley, 1998; Brown et al., 1994; Martin, 1994). These factors affect also woman-midwife relationship (Berg et al., 1996; Fraser, 1999; Hallsdorsdottir \& Karlsdottir, 1996).

However, in some cases the mother may be totally at the mercy of health professionals and therefore she feels vulnerable (Welburn, 1980). Loss of control (over what is happening or over her own body) is related to the concept of choice and is said to be one of the basic triggers for PND (Beck C.T., 1995a; Nicolson, 1998). The loss can provoke unfulfilled expectations about the birth process. A dehumanising process, technology and lack of information during labour can contribute to fear that provokes stress in mothers. Even with lots of support, the maternity ward is still unknown territory, which is why home births are sometimes desired by women (Welburn, 1980). The support of a companion in labour (usually the partner) is a bond with the "known world" that can positively affect the psychosocial state of the woman (Wolman et al., 1994).

\subsubsection{Postpartum}

The period immediately after the birth is a time of emotional and physical vulnerability. Women need support (informational, physical, psychological and social) (Raphael-Leff, 1991; Hobfoll et al., 1995; Magill-Cuerden, 2000)). One of the interventions of psychological support presents concept of debriefing, so that every woman is given an opportunity to discuss her labour, which is said to be helpful (Taylor, 1997; Lavender \& Walkinshaw, 1998). As its success largely depends on the quality of the relationship that the woman has with the person who provides the debriefing, it would be ideal if the midwife who cared for the woman antenatally continued to provide care after the birth. This would enable the midwife to use listening visits in pregnancy and debriefing at mutually convenient times (Littlewood \& McHugh, 1997).

During the first few days, it is important to be sensitive for signs of postpartum blues, since when this condition lasts for a longer period, can develop into PND. With appropriate interventions we can prevent more serious mental conditions can be prevented (Price, 2007). According to Bozoky \& Corwin (2002), PND can be prevented also through the treatment of postnatal fatigue, which untreated can lead to a downward spiral of postnatal mental disorders.

Some researchers blame early discharge for the development of PND, as women may not be prepared yet to take over the role of mother (Hickey et al., 1997). Ball (1982) states that the decision regarding the length of hospital stay should be made by the midwife in agreement with the woman. However, this can only be done if the midwife knows the mother from the pregnancy onwards. On the other hand, some studies have found that there is no connection between early discharge and PND if sufficient professional and non-professional support is 
available to the woman (Beck C.T. et al., 1992; Thompson et al., 2000). Returning home may be a pleasant but also a frustrating situation, when the mother feels responsible but lacks confidence with a new experience (Nicolson, 1998). Health professionals need to provide support in addition to professional help. This has been stated to be crucial (Nicolson, 1998), however, the term "psychosocial support « is hard to define. For some women this means practical help, while for others it means listening and emotional support (Clement \& Elliott, 1999). Women must be given the opportunity to talk freely about their concerns regarding parenting difficulties. Sometimes they just need a sympathetic ear or social support; mobilising friends and the community could help in such cases (Powell-Kennedy, 2002). The attachment with the child can be a reason for anxiety in women, therefore should be presented in a positive and relaxed manner (Welburn, 1980). Midwives should avoid giving conflicting advice as they may cause uncertainty for mothers and lower their self-esteem. They must help women to adapt to a new role (Bott, 1999). If their help is appropriate, they can efficiently cutdown the incidence of PND. Frequent visits during the first two postpartum months that adress women's needs, decrease incidence of PND for $40 \%$ (De Craene, 2002).

For all women, preventive screening should be performed by community midwives or nurses at six weeks, four and eight months postnatally. In case of any abnormalities, nurses and midwives could, on the basis of the screening test results, refer a woman to her general practitioner (SIGN, 2002; Holden, 1996). Mothers at risk can be given special support and observation by their caregivers (Holden et al., 1989; Clement, 1995; Brockington, 2000). A number of researchers have found that nurses and midwives can manage non-psychotic depression using counselling (Holden et al., 1989; Prendergast \& Austin 2001; Stewart \& Henshaw, 2002) and they can play a major role in the treatment of PND (Taylor, 1997). Littlewood \& McHugh (1997) identified seven basic principles in the philosophy of care for women with PND: assessment, relief of symptoms, maternal autonomy and self-esteem, individuality, universality, realism/ socialisation and group identity. These can all be incorporated within support groups (also for partners) and peer self-help groups that are facilitated by nurses and midwives. Educating women about PND and giving relevant advice can alleviate the guilt and shame they might be feeling (Powell-Kennedy et al., 2002; Brockington, 2002) and, in a non-judgemental environment, self-esteem may be enhanced. This is also an opportunity to check for signs of PND or identify mothers at risk (Cox, 1986). Health workers can also establish a support phone-line that would connect past sufferers of PND with women who currently have PND (Holden, 1996) or organise support groups for people who live with depressed women, to provide them with support and information (Gutteridge, 2000). It is said that depressive illness is the hardest mental condition for the family supporters, as it is quite capable of sapping the carer too (Kuipers \& Bebbington, 1997).

In more serious conditions, where medical treatment is needed, nurses and midwives can help women to make informed choices about their treatment. They can suggest them about available resources and treatment options (Beck C.T., 2002; Wood et al., 1997). And if the hospitalization is needed, women should be hospitalized with a baby (in mother-baby units); midwife can play an important role in fostering the relationship between mother and a child with help, support and possitive feedback (praise can raise mother's self esteem about being a mother) (WHO, 1991; Barnett \&Morgan, 1996).

The ideal approach is inter-disciplinary. Healing can be achieved only with collaborative work (Tully et al., 1998; Powell-Kennedy et al., 2002) and with the help of mental health 
professionals (Taylor, 1997). However one key element in this process is continuity of the caregiver, which can break the process of depersonalised care (Clement \& Eliott, 1999). Such care needs to be flexible and individually planned for each woman (MacArthur et al., 2002).

Despite very firm arguments that midwives can manage mild prenatal and postnatal mood disorders, different studies (Eden, 1989; Stewart \& Henshaw, 2002; Mivšek \& Hundley, 2006; Keng, 2005; Ross-Davie et al., 2006; Sullivan et al., 2003; Isik \& Bilgili, 2010) show that midwives are not prepared for this role.

\section{Methodology}

The question was, whether midwives are adequately prepared to take over the role of prevention and treatment of postnatal mood disorders and whether they feel prepared and willing to take over the responsibility for the care of these women.

Two stage study approach was therefore adopted. Results from 2003 study, which explored knowledge and opinions about PND of slovenian midwives and nurses who worked in the maternity hospital or in the community with pregnant, labouring or postnatal women (Skočir, 2004; Skočir \& Hundley, 2006; Mivšek et al., 2008) showed very clearly that they lack knowledge about postnatal mental health issues and therefore do not feel competent to take over more active role in the management of postnatal mental health disorders. 134 nurses and midwives participated in the study $(76,6 \%$ response rate). Only $24 \%$ of participants knew when PND usually bursts out and only 35\% correctly estimated the incidence of PND. They often confused symptoms of postnatal blues or psychosys with PND and rarely knew about screening tests for PND (21\%). Most of them knew only for medical options for the treatment of PND and were expressing low confidence in their ability to prevent, detect or manage postnatal mood disorders. $99 \%$ of them expressed the need for additional training in this field of care. One of main reccommendations of the study was that it is crucial to provide health workers who work with women in reproductive age with more information about mental health issues relevant for this population (Skočir, 2004; Skočir \& Hundley, 2006; Mivšek et al., 2008).

\subsection{Research design}

On the basis of the recommendations from the study in 2003 (Skočir, 2004; Skočir \& Hundley, 2006; Mivšek et al., 2008), the undergraduate study programme for midwives was implemented in 2004 with the lectures about postnatal mood disorders. The topic was included in the content of the subject Midwifery (in the third year of the study). Aim of the study was to explore whether educational intervention raised midwives' knowledge and affected their abilities in the management of postnatal mood disorders. The hypothesis tested in the study was that midwives, who finished the implemented midwifery study programme, with additional lectures in postnatal mental health issues, show greater knowledge about postnatal mood disorders, know to differentiate among different forms of postnatal mood disorders and express higher ability for management of those conditions. As the goal of this research was to explore and describe perceptions and experiences, a qualitative approach was adopted as suggested in the literature (Rezabek, 2000); questionnaire survey was used to gather the data. 


\subsection{Research tool}

The questionnaire used was the same as in the study in 2003 (Skočir, 2004; Skočir \& Hundley, 2006), developed on the basis of previously conducted focus groups (Skočir, 2004; Mivšek et al., 2008) and from concepts identified in the professional literature.

It covered four key topics: employment data, knowledge about PND, experiences and opinions about PND and demographic data. Most of the questions were closed with a variety of possible answers. Some questions included a category »other " to allow participants to add alternative responses. The section of the questionnaire that dealt with opinions and experiences used more subjective approaches and gave participants the opportunity to justify their choices with open questions. A 5-point Likert-type scale was used to assess participants' opinion of their role in the management of women with PND. In the last part of the questionnaire personal data were gathered and the participants were given an opportunity to add any information or explain things that they found unclear or irrelevant when completing the questionnaire (Skočir \& Hundley, 2006).

\subsection{Reliability and validity}

For the purpose of better reliability and validity of the study it is reccommended to use questionnaires which were tested already in previous surveys. Therefore the questionnaire from the 2003 study was used. Face and content validity of the questionnaire were assessed through review by colleagues, academic supervisors and experts in the fiel das suggested in the literature (Polit et al., 2001). The pilot study further assessed validity and asked participants whether they understood the questionnaire or had any queries; on the basis of pilot study some modifications were made (Skočir, 2004; Skočir \& Hundley, 2006).

\subsection{Sampling and study setting}

Five generations of midwifery students (150) attended the new midwifery study programme from 2004 in which curriculum of Midwifery was implemented with the lectures about postnatal mood disorders. Study sample was composed of those who already graduated (61).

\subsection{Data collection}

Questionnaires were distributed via mail in May 2011. The stamped envelope was included to the letter to raise response rate. Paricipant were asked to return the questionnaire within two weeks. After this time, written reminder was sent to all the participants and the deadline was extended fort two more weeks.

\subsection{Ethical considerations}

Participants'conntact details were obtained from the Faculty's register. Considering data protection act (Državni zbor RS, 1999), declaration was signed to use the data only for the purpose of the study and to assure participants of the study confidentiality. It was made clear to participants in the cover letter of the questionnaire that they could refuse to participate in the study and that their participation is anonimous. 


\subsection{Analysis}

The data were collated and entered into the SPSS database. Answers to the open-ended questions were grouped in the same cathegories as the data from the 2003 study. Descriptive statistics were produced for all variables. Data were compared with the results from the study performed in 2003 (midwives with higher education only) (Skočir, 2004) and statistical tests for significant differences were calculated.

\section{Results and discussion}

The study included 9 participants (29\%) in the 2003 group and 22 participants (79\%) in the 2011 group; alltogether 31 participants $(100 \%)$. They were all female, aged from 20 to 29 years with 1 to 5 years of working experience. They all had higher education; finished undergraduate midwifery study. Participants in 2011 study all undergone implemented programme which included 5 hour of lectures about postnatal mood disorders.

There were evident differences in the answers to the questions of both groups. The participants in 2011 group more often gave the expected answer to the question about the onset of PND; there was significant statistical difference between groups in this answer $(2 \hat{\mathrm{I}}=$ 11,064 , $\mathrm{df}=3$, sig. $=0,011$, however there were no improvements in estimation of the incidence of PND and they also underestimated the possibility of prenatal depression (Figure 2).

There were no significant differences in citing and ranking symptoms of PND. Both groups most often exposed weepiness as the main problem (100\% of participants in 2003 group and 97\% of respondents in 2011 group). The next most commonly quoted symptom was insomnia (93\%) in 2011 group and hallucinations (100\%) in 2003 group. The third most common symptom, as perceived by the participants, was tiredness (83\%) in 2011 group and guilt $(100 \%)$ in 2003 group. It can be said that there was a slight improvement in differentiating PND and puerperal psychosys in the 2011 group of participants, not exposing hallucinations as the main symptom of PND.

Obvious differences were found in testing the statements about detection of PND, as shown in Figure 3. Answers about the PND screening tests showed statistically significant differences between groups $(2 \hat{\mathrm{I}}=20,728, \mathrm{df}=4$, sig. $=0,000)$. Participants in 2011 group were more aware of screening possibilities for PND.

They were also more aware of existing support groups where they can refer woman who suffers from PND. Almost half of the participants in 2011 group knew support groups, while none of the participants in 2003 group knew any. The difference in the answers to this question was statistically significant $(2 \hat{\mathrm{I}}=7,970, \mathrm{df}=1$, sig. $=0,005)$.

As the first line treatment, participants in 2003 group cited counselling (50\%), as the second option they quoted medicaments (25\%) and psychotherapy (25\%). In the 2011 group, participants choose psychotherapy $(50 \%)$ or counselling $(25 \%)$ as the first line treatment, than support groups (20\%) and medicaments (4\%).

Many participants already had experiences in caring for women with diagnosed PND or for women they suspected suffering PND. Despite similar length of work in both groups, participants in 2011 group reported more women with PND they cared for $(35,7 \%)$ than 


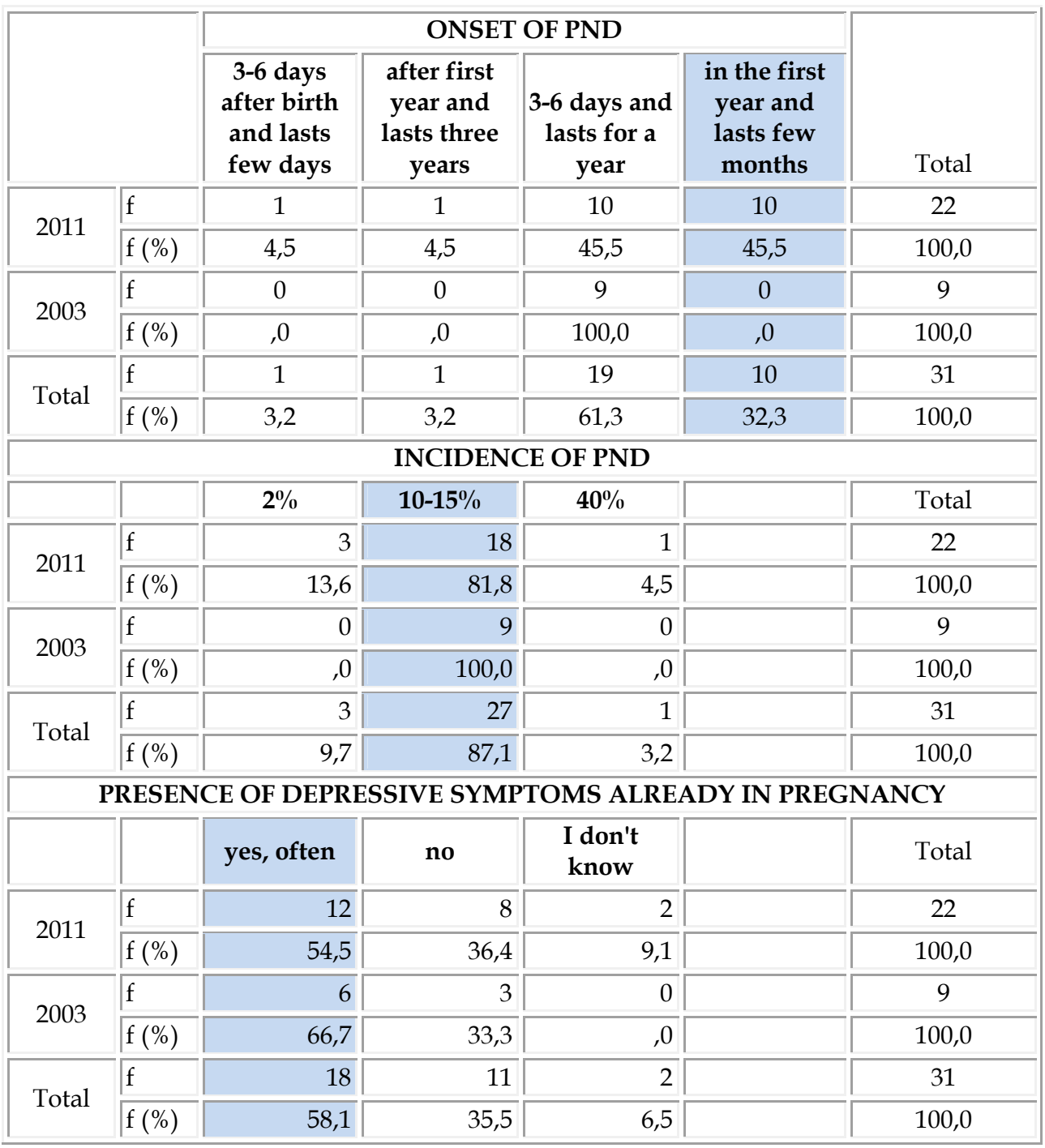

Fig. 2. Comparison of the answers about the facts on PND between the 2003 and 2011 group of participants. Expected answers are in blue fields.

participants in 2003 group (25\%). Even if the difference is not statistically significant it might be that with the educational intervention they become more sensitive for women's mental health issues.

They were also mora active in the management of those cases. The only action that participants in 2003 group mentioned was that they talked with women with PND and gave advice, however participants from 2011 group also notified woman's general practitioner, talked with woman's partner and referred woman to the therapists. 


\begin{tabular}{|c|c|c|c|c|c|c|c|}
\hline & \multicolumn{5}{|c|}{ EXISTENCE OF SCREENING TESTS FOR PND } & \multirow[b]{2}{*}{ Total } \\
\hline & & $\begin{array}{l}\text { there isn't } \\
\text { any }\end{array}$ & $\begin{array}{c}\text { yes, it } \\
\text { makes } \\
\text { diagnosys }\end{array}$ & $\begin{array}{c}\text { yes, but it } \\
\text { doesn't } \\
\text { make } \\
\text { diagnosys }\end{array}$ & $\begin{array}{l}\text { I don't } \\
\text { know }\end{array}$ & & \\
\hline \multirow{2}{*}{2011} & $\mathrm{f}$ & 2 & 1 & 15 & 4 & & 22 \\
\hline & $f(\%)$ & 9,1 & 4,5 & 68,2 & 18,2 & & 100,0 \\
\hline \multirow{2}{*}{2003} & $\mathrm{f}$ & 1 & 0 & 2 & 6 & & 9 \\
\hline & $f(\%)$ & 11,1 & , 0 & 22,2 & 66,7 & & 100,0 \\
\hline \multirow{4}{*}{ Total } & $\mathrm{f}$ & 3 & 1 & 17 & 10 & & 31 \\
\hline & $\mathrm{f}(\%)$ & 9,7 & 3,2 & 54,8 & 32,3 & & 100,0 \\
\hline & & \multicolumn{6}{|c|}{ PND SCREENING TESTS THAT YOU KNOW } \\
\hline & & $\begin{array}{c}\text { not } \\
\text { applicable }\end{array}$ & $\begin{array}{c}\text { I don't } \\
\text { know any }\end{array}$ & Beck C.T.'s & EPDS & $\begin{array}{l}\text { csale } \\
\text { euro5 }\end{array}$ & Total \\
\hline \multirow{2}{*}{2011} & $\mathrm{f}$ & 0 & 0 & 1 & 2 & 4 & 22 \\
\hline & $\mathrm{f}(\%)$ & , & , 0 & 14,3 & 28,6 & 57,1 & 100,0 \\
\hline \multirow{2}{*}{2003} & $\mathrm{f}$ & 7 & 1 & 0 & 0 & 0 & 9 \\
\hline & $f(\%)$ & 87,5 & 12,5 & 0 & 0 & , 0 & 100,0 \\
\hline \multirow{2}{*}{ Total } & $\mathrm{f}$ & 7 & 1 & 1 & 2 & 4 & 31 \\
\hline & $f(\%)$ & 46,7 & 6,7 & 6,7 & 13,3 & 26,7 & 100,0 \\
\hline
\end{tabular}

Fig. 3. Comparison of the answers about the screening on PND between the 2003 and 2011 group of participants. Expected answers are in blue fields.

Participants in 2003 group consider partner as the most appropriate person for detection of PND (75\%) and psyciatrists or psychologists as the most important for the treatment $(100 \%)$, while 2011 participants comprehend the responsibility for detection and treatment of PND more as a team work; their answers are very dispersed. They consider community nurses and midwives $(31 \%)$, partner $(24 \%)$, nurses and midwives in maternity hospital $(10 \%)$ and psyhologists $(10 \%)$ as the most appropriate people for detection of PND. As for the treatment, they quote psychologists and psyhiatrists $(66 \%)$ as the most appropriate, followed by community midwives and nurses and family (8\%). However the reasons for such choice are the same in both groups. The most important person for detection is chosen because of the regular contact with women and the most appropriate person for treatment is chosen on the basis of the professional knowledge about PND.

According to this, participants in 2011 group feel more responsible to take care for women's mental health in antenatal (education in antenatal classes), intrapartum (support during birth, debriefing) and postpartum period (detection, referrals, consultations). There were statistically significant differences between the groups particularly in the awareness of their role in support during labour $(\mathrm{t}=-2,778, \mathrm{df}=7,135$, sig. $=0,027)$, their role in detection of PND ( $\mathrm{t}=-2,953$, $\mathrm{df}=9,511$, sig. $=0,015)$ and their role in discussing PND with woman in antenatal classes $(2 \hat{\mathrm{I}}=11,476, \mathrm{df}=1$, sig. $=0,001)$. 
Perception of more active involvement in the management of mental health issues changed also their perception of the best place for treatment of woman with PND. More participants in 2011 group think that women should be treated at primary level of health care and stay at home with the family (66\%) than in 2003 group (56\%). However if they would need hospitalization due to severerity of illness, the participants in 2011 group prefer an option of woman to be accepted in psychiatry unit located in the maternity hospital $(31 \%)$ over the hospitalization in psychiatric hospital that 2003 group of participants chose most often $(25 \%)$; the answers showed statistically significant differences $(2 \hat{\mathrm{I}}=5,513, \mathrm{df}=1$, sig. $=0,019)$. Participants in 2011 also more frequently disagreed with the need of separation from the baby ( $83 \%$ vs $78 \%$ in 2003 group) as they felt that baby belongs with mother and that a childcare could be beneficial for woman (58\% in comparison with $18 \%$ in 2003 group).

Participants felt more prepared to manage postnatal mental health issues after the educational intervention, as shown in Figure 4, however the difference in answers was not significant.

\begin{tabular}{|c|c|c|c|c|c|}
\hline & \multicolumn{3}{|c|}{$\begin{array}{l}\text { SELF-CONFIDENCE FOR ACIVE ROLE IN } \\
\text { ADDRESSING POSTNATAL HEALTH ISSUES }\end{array}$} & \multirow[b]{2}{*}{ Total } \\
\hline & & not & $\begin{array}{l}\text { confident, so I } \\
\text { might could help }\end{array}$ & $\begin{array}{l}\text { very confident, I } \\
\text { could help the } \\
\text { woman }\end{array}$ & \\
\hline \multirow{2}{*}{2011} & $\mathrm{f}$ & 11 & 8 & 3 & 22 \\
\hline & $f(\%)$ & 50,0 & 36,4 & 13,6 & 100,0 \\
\hline \multirow{2}{*}{2003} & $\mathrm{f}$ & 8 & 1 & 0 & 9 \\
\hline & $f(\%)$ & 88,9 & 11,1 & , 0 & 100,0 \\
\hline \multirow{2}{*}{ Total } & $f$ & 19 & 9 & 3 & 31 \\
\hline & $\mathrm{f}(\%)$ & 61,3 & 29,0 & 9,7 & 100,0 \\
\hline
\end{tabular}

Fig. 4. Comparison of the answers about confidence in managing postnatal mental health problems between the 2003 and 2011 group of participants.

Despite raised awareness about their role in the management of postnatal mental health and greater subtlety for women's mental needs, there was not so much improvement in participants' knowledge as we expected and also they alone expressed desire for additional information and training. Unexpectedly participants in 2011 more often quoted the need for theoretical knowledge (57\%) than participants in 2003 group $(25 \%)$. It is possible that the educational intervention made them more critical about their knowing. They also wished opportunities for practical skills on counselling and leading postnatal support groups (40\% of participants in 2011 group). This might indicate that only theoretical intervention does not provide enough knowledge for midwives to be more confident. Counselling skills should be also provided as a practical component of additional training.

\section{Conclusion}

Approach to management of perinatal mental health issues is affected by the perception of cause. Doctors usually consider postnatal mood disorders pathological and treat them with 
medicines (Beck C.T., 2002b), while midwives, according to their philosophy about physiology of pregnancy, birth and the puerperium, might consider mild postnatal mood disorders normal response to the changes that occur in the puerperium and the demands of transition to parenthood. This argument support also the facts from the literature review; depression in postpartum is not more commom than in other periods of woman's life (CRAG, 1996), aetiology is unknown and varies individually, risk factors are therefore inconsistent (Robertson et al., 2004; Skočir, 2004; Wylie et al., 2011) and symptoms similar to normal changes of the puerperium (Yonkers et al., 2001). Some experts even claim that depression in the transition to motherhood is necessity - a kind o »recognition of imperfection " (Raphael-Leff, 1991) and »healthy rersponse to all the loss of the puerperium « (Stewart \& Henshaw, 2002). It could be stated that PND as such does not exists and is a product of medicalization of another part of woman's reproductive mental health (as PreMenstrual Syndrome - [PMS]). Life changes that demand alteration of lifestyle, social roles and relationships can be stressful for the individuals (Stowe \& Nemeroff, 1995). Postpartum period is demanding because of all the situations that need adaptations (Albers \& Williams, 2002). And the feelings of loss, anxiety and depression might be considered a normal response to these changes. However it is not clear at which point mother's physical exhaustion and sadness due to adaptation to parenthood convert into pathology. The most certain assumtion is that the causes and the development of postnatal mood disorders are very complex and individual. Therefore it is very important that there is certain continuity of carer who accompanies woman and her family through pregnancy, birth and postpartum and establish a relationship with the family that can be helpful in addressing also mental health issues.

Few interventions to reduce psychological morbidity of postnatal women have been successful, but obvious individualized continuous midwifery care (for example new models of midwifery-led care) have benefits on mothers' postnatal psychological well-being (MacArthur et al., 2002; Yaffe, 2002). This should be considered in development of policies for antenatal and postnatal care provision (Bick, 2003). Midwives, responsible for this role, however need educational interventions (Wheatley et al., 2003; Barnes, 2002) that include theoretical informations and practical counselling skills. Results of the study show similar results as others (Jardri et al., 2010); midwives benefit from educational interventions (Jardri et al., 2010). They perform their role more successfully and feel more confident.

\section{References}

[1] Affonso, D. D. (1992). Postpartum depression: A nursing perspective on women's health and behaviors. J Nurs Scholarsh, 24, pp. 215-221.

[2] Affonso, D. D., De, A. K., Horowitz, J. A. and Mayberry, L. J. (2000) An international study exploring levels of postpartum depressive symptomatology, J psychosom Res, 49(3), pp. 207-16.

[3] Aiken, C. (2000) "Post-natal depression: At home no one hears you scream". London: Jessica Kingsley publishers Ltd.

[4] Albers, L., Williams, D. (2002.) Lessons for US postpartum care. The Lancet, 359(2), pp.370-1. 
[5] Altschuler, L., Cohen, L., Moline, L., Kahn, D., Carpenter, D., Docherty, J. (2001). The expert consensus guideline series: Treatment of depression in women. New York: McGraw Hill.

[6] APA (1994) Diagnostic and statistical manual of mental disorders IV th ed. Washington: APA.

[7] APA. (2000). Diagnostic and statistical manual of mental disorders IV 4th TR. Washington, DC: Task Force.

[8] Appleby, L., Gregoire, A., Platz, C., Prince, M. and Kumar, R. (1994) “Screening women for high risk of postnatal depression", Journal of psychosomatic research, 38(6), pp. 539-45.

[9] Armstrong, K. and Edwards, H. (2003) "The effect of exercise and social support on mothers reporting depressive symptoms: a pilot randomised controlled trial", International journal of mental health nursing, 12(2), pp. 130-8.

[10] Austin, M. P. and Lumley, J. (2003) "Antenatal screening for postnatal depression: a systematic review", Acta Psychiatr Scand, 107(1), pp. 10-7.

[11] Ball, J. (1982) "Stress and the postnatal care of women", Nursing times, 78(45), 1904-7.

[12] Barnes, S.L. (2002). What midwives need to know about postpartum depression. MIDIRS Midwifery digest, 61,pp. 18-9.

[13] Barnett, B., Morgan, M. (1996). Postpartum psychiatric disorders - who should be admitted and to which hospital? Aust N Z J Psychiatry, 30(6),pp. 709-14.

[14] Beck C.T., A. T., Ward, C. H., Mendelson, M., Mock, J. and Erbaugh, J. (1961). An inventory for measuring depression, Arch gen psychiatry, 4, pp.561-71.

[15] Beck C.T. (1992) The lived experience of postpartum depression: a phenomenological study, Nurs Res, 41(3), pp.166-70.

[16] Beck C.T.(1993). Teetering on the edge: a substantive theory of postpartum depression, Nurs Res, 42(1), pp.42-8.

[17] Beck C.T. (1995a) Screening methods for postpartum depression, JOGNN, 24(4), pp.30812.

[18] Beck C.T. (1995b) Perceptions of nurses' caring by mothers experiencing PND, JOGNN, 24(9), pp.819-25.

[19] Beck C.T. (1996). A meta-analysis of predictors of postpartum depression, Nurs Res, 45(5), pp.297-303.

[20] Beck C.T. (1998). A check list to identify women at risk for developing postpartum depression, JOGNN, 27(1), pp.39-45.

[21] Beck C.T. (2002) Theoretical perspectives of postpartum depression and their treatment implications, MCN, 27(5), pp.282-7.

[22] Beck C.T., Gable, R. K. (2000). Postpartum depression screening scale: development and testing, Nurs Res, 49(5), pp.272-82.

[23] Beck C.T., Gable, R. K. (2001). Further validation of the postpartum depression screening scale, Nurs Res, 50(3), pp.155-64.

[24] Beck C.T., Reynolds, M. A. and Rutowsky, P. (1992). Maternity blues and postpartum depression, JOGNN, 21(4), pp.287-93.

[25] Benner-Carson, V. (2000) Mental health nursing 2nd ed. Philadelphia: W.B. Saunders company.

[26] Berg, M., Lundgren, I., Hermansson, E., Wahlberg, V. (1996). Women's Experience of The encounter with the Midwife during Childbirth. Midwifery, 12, pp.11-15.

[27] Bick, D. (2003). Strategies to reduce postnatal psychological morbidity: the role of midwifery services. Dis manage health outcomes, 11(1), pp.11-20. 
[28] Boath, E. and Henshaw, C. (2001) “The treatment of PND: a comprehensive literature review, Journal of reproductive and infant psychology, 19(3), pp.215-48.

[29] Bott, J. (1999) Reflections on PND, British journal of midwifery, 7(1),pp. 45-8.

[30] Bozoky, I. and Corwin, E. J. (2002) Fatigue as a predictor of postpartum depression, JOGNN, 31(4), pp.436-43.

[31] Bowe, S. and Watson, A. (2001) "Perinatal depression: a randomised controlled trial of an antenatal education intervention for primiparas", Obstetrical and gynaecological survey, 56(10), pp. 597-9.

[32] Braverman, J. and Roux, J. (1978) "Screening for the patients at risk for postpartum depression", Obstetrics and gynaecology, 52(6), pp. 731-6.

[33] Brochington, J. F. (1992) Disorders specific to the puerperium, Int J Ment Health, 21(2),pp. 41-5.

[34] Brochington, J. F., Martin, C., Brown, G. W., Goldberg, D. and Margison, F. (1990) Stress and puerperal psychosis, Br J psychiatry, 157(september), pp.331-4.

[35] Brockington, J. (2000) Postnatal illness: the professional view, In: Aiken, C. PND - at home no one hears you scream. London: Jessica Kingsley publishers Ltd.

[36] Brown, S., Lumley, J. (1998). Changing Childbirth: Lessons from an Australian Survey of 1336 women. Br J Obstet Gynecol, 105, pp.143-155.

[37] Brown, S., Lumley, J., Small, R., Astbury, J. (1994). Missing Voices: The Experience of Motherhood. New York: Oxford University Press.

[38] Buist, A. (1997) Postpartum psychiatric disorders - guidelines for management, CNS drugs, 8(2), pp.113-23.

[39] Burke, L. (2003). The impact of maternal depression on familial relationships. International Review of Psychiatry, 15, pp. 243-255.

[40] Campbell, S.B., Cohn, J.F., Flanagan, C. ,Popper S., Meyers, T. (1992) Course and correlates of postpartum depression during the transition to parenthood. Dev. Psychopathol.4, pp. 29-47.

[41] Clarke-Akalanue, E. and Myles, P. (2002) Supporting new mothers with PND: an evaluation, J Community Nurs, 16(12), pp.18-20.

[42] Clement, S. (1995) Listening visits in pregnancy: a strategy for prevention PND, Midwifery, 11(2), pp.75-80.

[43] Clement, S. and Elliott, S. (1999) Psychological health before, during and after chilbirth, In: Marsh, G. and Renfrew, M. Community based maternity care. Oxford: Oxford university press.

[44] Chilvers, C., Dewley, M., Fielding, K., Gretton, V., Miller, P., Palmer, B., Weller, D., Churchill, R., Williams, I., Bedi, N., Duggan, C., Lee, A. and Harrison, G. (2001) "Antidepressant drugs and generic counselling for treatment of major depression in primary care: randomised trial with patient preference arms", British medical journal, 322(7289), pp. 722-75.

[45] Combes, G. and Schonveld, A. (1992) Life will never be the same again: A review of antenatal and postnatal health education. London: Health education authority.

[46] Cooper, P.J., Murray, L. (1998) Clinical review - fortnightly review: postnatal depression. BMJ,316(7148),pp.1884-6.

[47] Cooper, P.J., Murray, L., Hooper, R., West, A.( 1996) The development of a predictive index for postpartum depression. Psychol Med 26,pp. 627- 634. 
[48] Cooper, P.J., Murray, L., Wilson, A. and Romaniuk, H. (2003) “Controlled trial of the short and long term effect of psychological treatment of post-partum depression", British journal of psychiatry, 182 (May), pp. 412-9.

[49] Corral, M., Kuan, A. and Kostaras, D. (2000) "Bright light therapy's effect on postpartum depression", American journal of psychiatry, 157(2), pp. 303-4.

[50] Cox, J. L. (1986) PND - a guide for health professionals. Edinburgh: Churchil Livingstone.

[51] Cox, J.L. (2004) Postnatal mental disorder: towards ICD-11 World Psychiatry. 2004, 3(2),pp.96-97.

[52] Cox, J. L., Holden, J. M., Sagovsky, R. (1987) Detection of postnatal depression. Development of the 10-item Edinburgh Postnatal Depression Scale. Br J Psychiatry, 150, pp. $782-786$.

[53] CRAG working group on maternity services (1996) Report on detection and early intervention in PND. URL www.show.scot.nhs.uk/crag - last accessed December 2010

[54] Dalton, K. and Herxheimer, A. (1997) Treatment of PND. Additional information would enhance value of the study, BMJ, 315(7100), p.122.

[55] Dean, C. and Kendall, R. E. (1981) The symptomatology of puerperal illness, $\mathrm{Br}$ J Psychiatry, 139(2), pp.128-33.

[56] DeAngelis, T. (1997) There's a new hope for women with postpartum blues, American psychological association monitor, p.22.

[57] De Caene, M. (2002). Postnatal pampering: Midwives can prevent postpartum depression. Psychology today. May 2002.

[58] Dennis, C., Hodnett, E., Kenton, L. et al. (2009). Effect of peer support on prevention of postnatal depression among hig risk women: Multisite randomised controlled trial. BMJ, 338 (a3064), pp. 1-9.

[59] Dennis, C.L., Creedy, D. (2004). Psychosocial and psychological interventions for preventing postpartum depression. Cochrane database of systematic reviews,p. 4.

[60] Dietch, K. V. and Bunney, B. (2002) The silent disease: diagnosing and treating depression in women, Lifeliness, 6(2), pp.140-5.

[61] Dombrowski, M. A. S., Anderson, G. C., Santori, C. and Burkhammer, M. (2001) "Kangaroo (skin to skin) care with a postpartum women who felt depressed", American journal of maternal child nursing, 26(4), pp. 214-6.

[62] Driscoll JW. (2006) Postpartum depression. How nurses can identify and care for women grappling with this disorder. AWHONN Lifelines,10(5), pp.400-409.

[63] Državni zbor RS (1999) Zakon o varstvu osebnih podatkov. Uradni list RS, 59/99.

[64] Eden, C. (1989) Midwives knowledge and management of PND, Aust J Adv Nurs, 7(1),pp. 35-42.

[65] Eberhard-Gran, M., Eskild, A., Tambs, K., Opjordsmoen, S. and Samuelsen, S. (2001) "Review of validation studies of the EPDS", Acta Psychiatr Scand, 104(4), pp. 243-9.

[66] Elliot, S., Ross-Davie, M., Sarkar, A., Green, C. (2007). Detection and intial assesment of mental disorder:the midwifes role. The british journal of midwifery, 15(12), pp.759764.

[67] England, S. J., Ballard, C. and George, S. (1994) "Chronicity in postnatal depression", European journal of psychiatry, 8(2), pp. 93-6.

[68] Fraser, D.M. (1999). Women's Perceptions of Midwifery Care: A Longitudinal Study to Shape Curriculum Development. Birth, 26, pp.99-107. 
[69] Freeman, M. P., Wright, R., Watchman, M., Wahl, R. A., Sisk, D. J., Fraleigh, L., Weibbrecht, J. M. (2005). Postpartum depression assessments at well-baby visits: Screening feasibility, prevalence, and risk factors. Journal of Women's Health, 14(10), pp. 929-935.

[70] Gatrell, C. (2005). Hard labour: the sociology of parenthood. New York: Open University Press.

[71] Glover, V., Liddle, P., Taylor, A., Adams, D., Landler, M. (1994) Mild hypomania (the highs) can be a feature of the first post-partum week: association with later depression. Br J psychiatry ,164(4),pp.517-521.

[72] Goldman, R. D. and Koren, G. (2003) “Mothersrisk update: Taking St. John's wort during pregnancy", Canadian family physician, 49(january), pp.29-30.

[73] Green, J.M., Murray, D. (1994). The use of EPDS in research to explore the relationship between antenatal and postnatal dysphoria. In: Cox, J., Holden, J, eds. Perinatal psychiatry - use and misuse of the EPDS. London: Royal College of psychiatrists.

[74] Gregoire, A. J., Kumar, R., Everitt, B., et al(1996)Transdermal oestrogen for treatment of severe postnatal depression. Lancet, 347,pp.930-933.

[75] Gutteridge, K. (2001) The Tamworth PND support group, Midwifery digest, 11(1), Suppl. 1, pp.17-9.

[76] Hagen, E. H. (1999). The functions of postpartum depression. Evolution and Human Behavior, 20,pp. 325-359.

[77] Hall, L. A., Kotch, J. B., Browne, D. and Rayens, M. K. (1996) "Self esteem as a mediator of the effects of stressors and social resources on depressive symptoms in postpartum mothers", Nursing research, 45(4), pp. 231-8.

[78] Hallsdorsdottir, S., Karlsdottir, A.I. (1996). Journeying through Labour and Delivery: Perceptions of Women who have Given Birth. Midwifery, 12, pp.48-61.

[79] Hanusa, B.H., Scholle, S.H., Haskett, R.F., Spadaro, K., Wisner, K.L.(2008) Screening for depression in the postpartum period: A comparison of three instruments. $J$ Women's Health, 17,pp.585-596.

[80] Hearn, G., Iliff, A., Jones, I., Kirby, A., Ormiston, P., Parr, P., Rout, J. and Wardman, L. (1998) PND in the community, Br J Gen Pract, 48(428), pp.1064-6.

[81] Hewitt, C. E., Gilbody, S. M., Brealey, S., Paulden, M., Palmer, S., Mann, R. (2009) Methods to identify postnatal depression in primary care: an integrated evidence synthesis and value of information analysis. Health Technol Assess,13(36), pp.1-145, 147-230.

[82] Hickey, A. R., Boyce, P. M., Ellwood, D. and Morris-Yates, A. D. (1997) Early discharge and risk for PND, Med J Aust, 167(5), pp.244-7.

[83] Hirst, K.P., Moutier, C.Y.(2010) Postpartum major depression. Am Fam Physician,82(8),pp.926-33.

[84] Hillan, E. (1992). Issues of delivery in midwifery care. JAN, 17(3),pp.274-278.

[85] Hobfoll, S.E., Ritter, C., Lavin, J., Hulsizer, M.R., Cameron, R.P. (1995). Depression prevalence and incidence among inner-city pregnant and postpartum women. J Consult Clin Psychol, 63(3), pp.445-53.

[86] Hodnett, E. (1996) Nursing support of the labouring women, JOGNN, 25(3), pp.257-64.

[87] Holcomb, W.L.J., Stone, L.S., Lustman, P.J., et al., 1996. Screening for depression in pregnancy: characteristics of the Beck Depression Inventory. Obstet Gynecol, 88 (6), pp.1021- 1025 . 
[88] Holden, J. M., Sagovsky, R. and Cox, J. L. (1989) Counselling in a general practice setting: controlled study of health visitor intervention in treatment of PND, BMJ, 298(6668), pp.223-6.

[89] Holden, J. M. (1991). Postnatal depression: its nature, effects, and identification using the Edinburgh Postnatal Depression scale. Birth, 18(4),pp. 211-221.

[90] Holden, J. (1996) "The role of health visitors in postnatal depression", International review of psychiatry, 8(1), pp. 79-86.

[91] Huang, Y. and Mathers, N. (2001) PND - biological or cultural? A comparative study of postnatal women in United Kingdom and Taiwan, JAN, 33(3), pp.279-87.

[92] Isik, S.N., Bilgili, N. (2010). PND: midwives' and nurses' knowledge and practices. Embase Erciyes Tip Dergisi, 32(4), pp.265-74.

[93] Jardri, R., Maron, M., Pelta, J., Thomas, P., Codaccioni, X., Goudemand, M., Delion, P. (2010). Impact of midwives training on PND screening in the first week post delivery: a quality improvement report. Midwifery, 26, pp.622-9.

[94] Jones, I., Craddock, N., (2001). Familiality of the puerperal trigger in Bipolar Disorder: results of a family study. American Journal of Psychiatry,158,pp.913-917.

[95] Josefsson, A., Berg, G., Nordin, C. and Sydsjo, G. 2001. Prevalence of depressive symptoms in late pregnancy and postpartum. Acta Obstetricia et Gynecologica Scandinavica, 80(3), pp.251-255.

[96] Karuppaswamy, J. and Vlies, R. (2003) "The benefit of oestrogens and progestogens in postnatal depression", Journal of obstetrics and gynaecology, 23(4), pp. 341-6.

[97] Kitzinger, S. (1994). Me, matere. Ljubljana: Ganeš.

[98] Keng, S. L. (2005). Malaysian midwives' views on PND. British journal of midwifery, 13(2), pp.78-86.

[99] Kuipers, E. and Bebbington, P. (1997) Living with mental illness - a book for relatives and friends. $2^{\text {nd }}$ rev ed. London: Souvenir press.

[100] Lavender, T. and Walkinshaw, A. (1998) "Can midwives reduce postpartum psychological morbidity?: a randomised trial", Birth, 25(4),pp. 215-9.

[101] Lawrie, T. A., Herxheimer, A. and Dalton, K. (2003) "Oestrogens and progestogens for preventing and treating postnatal depression", The Cochrane library, 4(2).

[102] Lee, D. T. S., Yip, A. S. K., Chiu, H. F. K. and Chung, T. K. H. (2000) “Screening for postnatal depression using the double -test strategy", Psychosom Med, 62(2), pp. 258-263.

[103] Letourneau NL, Fedick CB, Willms JD, Dennis CL, Hegadoren K, Stewart MJ. Longitudinal study of postpartum depression, maternal-child relationships and children's behaviour to 8 years of age. In: Devore D, editor. Parent-child relations: New research. New York: Nova Science; 2006. pp. 45-63.

[104] Lasa, L., Ayuso-Mateos, J. Vázquez-Barquero, J. L., et al (2000) The use of the Beck Depression Inventory to screen for depression in the general population: a preliminary analysis. J Affect Disord, 57,pp. 261 -265.

[105] Lavender, T. and Walkinshaw, A. (1998) Can midwives reduce postpartum psychological morbidity?: a randomised trial, Birth, 25(4), pp.215-9.

[106] Lazzare J. The mother knot. Durham: Duke University Press, 1997.

[107] Leathers, S. J., Kelley, M. A. and Richman, J. A. (1997) Postpartum depressive symptomatology in new mothers and fathers: parenting, work and support, The journal of nervous and mental disease, 185(3), pp.129-39. 
[108] Lee, D. T. S., Chung, T. K. H. (2007). PND: an update. Best Pract Res Clin Obstet Gynecol, 21(2), pp.183-191.

[109] Leonard, L. G. (1998) Depression and anxiety disorders during multiple pregnancy and parenthood, JOGNN, 27(3), pp.329-37.

[110] Lepper, H. S., DiMatteo, M. R. and Tinsley, B. J. (1994) Postpartum depression: how much do obstetric nurses and obstetricians know?, Birth, 21(3), pp.149-54.

[111] Ličina, M. and Radovanovič, M. (1995) Poporodne duševne motnje s poudarkom na poporodni depresivni simptomatiki, Medicinski razgledi, 34(2), pp.245-63.

[112] Littlewood, J. and McHugh, N. (1997) Maternal distress and PND: the mith of Madonna. Houndsmills: MacMillan.

[113] LoCicero, A. K., Weiss, D. M. and Issokson, D. (1997) Postpartum depression: a proposal for prevention through an integrated care and support network, Applied and preventive psychology, 6(4), pp.169-78.

[114] MacArthur, C., Winter, H. R., Bick, D. E., Knowles, H., Lilford, R., Henderson, C., Lancashire, R. J., Braunholtz, D. A. and Gee, H. (2002) Effects of redesigned community postnatal care on women's health four months after birth: a cluster randomised controlled trial, The Lancet, 359(2), pp.378-85.

[115] Magill-Cuerden, J. (2000). Social support in pregnancy: midwives have a crucial role to play. British journal of midwifery, 14(3), p.156.

[116] Marks, M. N., Siddle, K., Warwick, C. (2003). Can we prevent PND? A randomised controlled trial to assess the effect of continuity of midwifery care on rates of PND in high risk women. J Matern Fetal Neonatal Med, 13 (2), pp.119-223.

[117] Martin, C. (1994). How do you Count Maternal Satisfaction? A User-commissioned Survey of Maternity Services. In: Roberts, H., ed. Women's Health Counts. London: Routledge, pp.6-20.

[118] Mauthner, N. S. (1999) Feeling low and feeling really bad about feeling low: women's experiences of motherhood and postpartum depression, Canadian psychology, 40(2), pp.143-61.

[119] McCarthy, A. (1998) PND: diagnosis and treatment. Ir Med J, 91 (2S),p. 44.

[120] McIntosh, J. (1993) Postpartum depression: women's help-seeking behaviour and perceptions of cause, JAN, 18(2), pp.178-84.

[121] McQueen A, Mander R. (2003). Tiredness and fatigue in the postnatal period. JAN, 42(5), pp.463-9.

[122] Meager, I. and Milgrom, J. (1996) "Group treatment for postpartum depression", Australian and New Zeland journal of psychiatry, 30(6), pp. 852-60.

[123] Miller, L. J. (2002). Postpartum depression. Journal of the American Medical Association, 287, pp. 762-765.

[124] Misri, S. , Kostaras, X. (2002). Benefits and risks to mother and infant of drug treatment for postnatal depression. Drug Safety, 25 (13),pp. 903-911.

[125] Mivšek AP, Hundley V, Kiger A. (2008). Slovenian midwives' and nurses' views on postnatal depression: an exploratory study. Int Nurs Rev 55(3), pp. 320-6.

[126] Mivšek, A.P. (2007). Slovenske ženske v pričakovnju: Sprijaznjene in pasivne ali aktivne in zadovoljne uporabnice obporodnega zdravstvenega varstva. In: Drglin Z, ed. Rojstna mašinerija. Sodobne obporodne vednosti in prakse na Slovenskem. Koper: Založba Annales, pp.73-103.

[127] Multidisciplinary working group for Grampian (2001). PND protocol for Grampian: redesign of PND pathway. Unpublished draft. 
[128] Murray, D. (1996) Oestrogen and PND, The Lancet, 347(9006),pp. 918-9.

[129] Murray ,L., Cox, J.L. (1990) Screening for depression during pregnancy with the Edinburgh Depression Scale (EPDS). J. Infant Reprod. Psychol,8, pp. 99-107.

[130] Musek, J. (1995). Ljubezen, družina, vrednote. Ljubljana: EDUCY.

[131] Nastran Ule, M. (1993). Psihologija vsakdanjega življenja. Ljubljana: Znanstveno in publicistično središče.

[132] National Institute for Health and Clinical Excellence (2007) Intrapartum care. London: National Institute for Health and Clinical Excellence.

[133] Nicolson, P. (1998) Post-natal depression; psychology, science and the transition to motherhood. London: Routledge.

[134] Noh, P. (1987) Postpartum depression: extent, timing and persistence of emotional disorders following childbirth. Br J Psychiatry, 151, pp. 523-7.

[135] Nolan, M.L. (1997). Antenatal education- where next? JAN, 25, pp.1198-1204.

[136] Nonacs, R., Cohen, L.S. (2002). Depression during pregnancy: diagnosis and treatment options. J Clin Psychiatry, 63 Suppl 17, pp.24-30.

[137] Nott, P.N., Franklin, M. ,Armitage, C., Gelder, M.G. (1976) Hormonal changes and mood in the puerperium, Br. J. Psychiatry, 128, pp. 379-383.

[138] Oakley, A. (1993). Becoming a Mother. Oxford: Martin Robertson.

[139] O'Hara, M.W., Neunaber, D.J., Zekoski, E.M. (1984) Prospective study of postpartum depression: prevalence, course, predictive factors. J Abnorn Psychol, 93, pp. 158-181.

[140] O'Hara, M. W., Zekoski, E. M., Phillips, L. H. and Wright, E. J. (1990) Controlled prospective study of postpartum mood disorders: comparison of childbearing and non-childbearing women, J Abnorm Psychol, 99(1), pp.3-15.

[141] O'Hara, M. W., Stuart, S., Gorman, L. L. and Wenzel, A. (2000) "Efficacy of interpersonal psychotherapy for postpartum depression", Archives of general Psychiatry, 57(11), pp. 1039-45.

[142] Okano, T., Nagata, S., Hasegawa, M., Nomura, J. and Kumar, J. (1998) Effectiveness of antenatal education about PND: a comparison of two groups of Japanese mothers, Journal of mental health, 7(2),pp. 191-8.

[143] Oren, D. A., Wisner, K. L., Spinelli, M., Epperson, C. N., Peindl, K. S., Terman, S. U., J. and Terman, M. (2002) "An open trial of morning light therapy for treatment of antepartum depression", The American journal of psychiatry, 159(4), pp. 666-9.

[144] Pairman, S., Tracy, J., Pincombe, C., Thorogood, F., eds. (2006). Midwifery: Preparation for Practice. Sydney: Elsevier.

[145] Pajntar, M. (1994) Poporodne depresije. In: Pajntar, M. and Novak Antolič, Ž. (1994) Nosečnost in vodenje poroda. Ljubljana: Cankarjeva založba.

[146] Paykel, E. S. (2000) Classification of postpartum disorders in ICD 10 and DSM IV, The Marce society newsletter, p.9.

[147] Pitt, B. (1968) Atypical depression following childbirth, Br J Psychiatry, 114(516), pp.1325-35.

[148] Petrick, J. (1984) "Postpartum depression: identification of high risk mothers", Journal of obstetrics, gynaecology and neonatal nursing, 13(1), pp. 37-40.

[149] Pinkofsky, H. B. (2000) "Effects of antipsychotics on the unborn child: what is known and how should this influence prescribing", Paediatric drugs, 2(2), pp.83-90.

[150] Polit, D. F., Beck C.T., C.T. and Hungler, B. P. (2001). Essentials of nursing researchmethods, appraisal and utilization. 5th ed. Philadelphia: Lippincot. 
[151] Posner, N.A., Unterman, R.R., Williams, K.N., Williams, G.H. (1997), Screening for postpartum depression. An antepartum questionnaire. J Reprod Med, 42. pp. 207-215.

[152] Postnatal and Antenatal Depression Association (PaNDa). Information package. Melbourne: PaNDa, 2001.

[153] Powell-Kennedy, H., Beck C.T., C.T. and Driscoll, J. W. (2002) A light in the fog: caring for women with postpartum depression, J Midwifery Women Health, 47(5), pp.318-30.

[154] Prendergast, J. and Austin, M. P. (2001) Early childhood nurse delivered cognitive behavioural counselling for post-natal depression, Australian psychiatry, 9(3), pp.255-9.

[155] Price, S., ed. (2007). Mental health in pregnancy and childbirth. Edinburgh: Elsevier Churchill Livingstone.

[156] Priest, S. R., Henderson, J., Evans, S. F. and Hagan, R. (2003) "Stress debriefing after childbirth: a randomised controlled trial", Medical journal of Australia, 178(11), pp.542-5.

[157] Raphael-Leff, J. (1991) Postnatal psychological complications, In: Psychological processes of childbearing. London: Chapman and Hall.

[158] Renkert, S., Nutbeam, D. (2001) Opportunities to improve maternal health literacy through antenatal education: an exploratory study. Health Promot Int, 16(4), pp.381-388.

[159] Rezabek, R. (2000) Online focus groups: electronic discussions for research. Forum: Qualitative social research. URL http://www.qualitative-research.net/fgs - last accessed February 2011.

[160] Richards, J.P. (1990) Postnatal depression: A review of recent literature. Br J Gen Pract, 40: pp. 472-476

[161] Righetti-Veltema, M., Bousquet, A., \& Manzano, J. (2003). Impact of postpartum depression symptoms on mother and her 18-month old infant. European Child and Adolescent Psychiatry, 12. pp. 75-83.

[162] Ritter, C., Hobfoll, S. E., Lavin, J., Cameron, R. P., \& Hulsizer, M. R. (2000). Stress, psychosocial resources, and depressive symptomatology during pregnancy in lowincome inner-city women. Health Psychology, 19, pp. 576-585.

[163] Robertson, E., Grace, S., Wallington, T., Stewart, D.E. (2004). Antenatal risk factors for postpartum depression: A synthesis of recent literature. Gen Hosp Psychiatry, 26, pp. 289-295.

[164] Robling, S. A., Paykel, E. S., Dunn, V. J., Abbott, R., Katona, C. (2000). Long-term outcome of severe puerperal psychiatric illness: a 23 year follow-up study. Psychological Medicine, 30, pp. 1263-1271.

[165] Ross-Davie, M., Elliot, S., Sarkar, A., Green, L. (2006). A public health role in perinatal mental health: are midwives ready? British journal of midwifery, 14(6), pp. 330-4.

[166] Sampselle, C., Seng, J., Yeo, S., Killion, C. and Oakley, D. (1999) "Physical activity and postpartum well-being", Journal of obstetrics gynaecologic and neonatal nursing, 28(1), pp.41-9.

[167] Sand Sobey, W. (2002) Barriers to postpartum depression prevention and treatment: a policy analysis, J Midwifery Women Health, 47(5),pp. 331-6.

[168] Scott, A.I.F. (1997) Treatment of postnatal depression. BMJ, 315(7100), p. 122.

[169] Schnyer, R. N., Manber, R. and Fitzcharles, A. J. (2003) "Acupuncture treatment for depression during pregnancy: conceptual framework and two case reports", Alternative health practitioner, 8(1), pp. 40-53.

[170] Shu-Shya, H., Yu-Ying, F. (2003) Effectiveness of informational support in reducing the severity of postnatal depression in Taiwan. Journal of Advanced Nursing, 42(1), pp.30-36. 
[171]SIGN (2002). PND and puerperal psychosis: a national clinical guideline 60 . Edinburgh: SIGN.

[172] Simkin, P. (1996) The experience of maternity in a woman's life, JOGNN, 25(3), pp.247-52.

[173] Sit, D.K., Wisner, K.L.(2009) Identification of postpartum depression. Clin Obstet Gynecol ,52,pp.456-468.

[174] Skočir AP. (2004) Midwives' and nurses' perception of their role in the prevention, detection and management of postnatal depression. MSc thesis. Aberdeen: University of Aberdeen

[175] Skočir AP, Hundley V. (2006) Are Slovenian midwives and nurses ready to take on a greater role in caring for women with postnatal depression. Midwifery 22(1): 40-55.

[176] Slade, P., MacPherson, S.A., Hume, A., Maresh, M. (1993). Expectations, Experiences and Satisfaction with Labour. Br J Clin Psychol, 32,pp. 469-483.

[177] Small, R., Lumley, J., Donohue, L. S., Potter, A. and Waldenstrom, U. (2000) "Randomized controlled trial of midwife-led debriefing to reduce maternal depression after operative childbirth", British medical journal, 321(7268), pp. 1043-7.

[178] Sobey, W. S. (2002). Barriers to postpartum depression prevention and treatment: A policy analysis. Journal of Midwifery and Women's Health, 47, pp. 331-336.

[179] Spinelli MG. (1997) Interpersonal psychotherapy for depressed antepartum women: a pilot study. Am J Psychiatry,154(7), pp.1028-30.

[180] Stamp, G., Williams, A. and Crowther, C. (1996) "Predicting postnatal depression among pregnant women", Birth, 23(4), pp. 218-23.

[181] Stewart, C. and Henshaw, C. (2002) Midwives and perinatal health, British journal of midwifery, 10(2), pp.117-21.

[182] Stocky A. ,Lynch J. (2000). Acute psychiatric disturbance in pregnancy and puerperium. Balliere's Clin. Obstet. Gynaecol. 14 ,pp. 73-87

[183] Stowe, Z. N. and Nemeroff, C. B. (1995) Women at risk for postpartum onset major depression, Am J Obstet Gynecol, 173(2), pp.639-45.

[184] Stowe, Z.N., Levy, S.T., Nemeroff, C.B. (1997)Comorbid postpartum depression and bereavement: a complicated case. Am J Psychiatry, 154(3), pp. 418-422.

[185] Stuchbery, M., Matthey, S. and Barnett, B. (1998) PND and social support in Vietnamese, Arabic and anglo-celtic mothers, Soc Psychiatry Psychiatr Epidemiol, 33(10), pp.483-90.

[186] Sullivan, A., Raynor, M., Oates, M. (2003). Why mothers die: perinatal mental health. British journal of midwifery, 11, pp.310-2.

[187] Svensson, J., Barclay, L., Cooke, M. (2009). Randomised-controlled trial of two antenatal education programmes. Midwifery, 25, pp.114-124.

[188] Taylor, A. (1997) Out of the blues, Nursing times, 93(45), p.18.

[189] Thompson, J. F., Roberts, C. L., Currie, M. J. and Ellwood, D. A. (2000) Early discharge and PND - a prospective cohort study, Med J Aust, 172(11), pp.532-5.

[190] Thoits PA. Self-labelling processes in mental illness: the role of emotional deviance. Am J Socio, 91,pp.221-49.

[191] Thurtle, V. (1995) Post-natal depression: the relevance of sociological approaches, JAN, 22(3), pp.416-24.

[192] Tiran, D. (2002) “Bailliere's midwives' dictionary". 9th ed. Edinburgh: Elsevier science limited.

[193] Tully, C., Watson, C. and Abrams, A. (1998) PND: training health visitors to use the EPDS, Community practitioner, 71(6), pp.213-5. 
[194] Yaffe, M. (2002). Midwife-led postnatal care with individual needs assessment may reduce PND. Evidence-based healthcare, 6(3), pp.117-8.

[195] Yonkers, K. A., Ramin, S. M., Rush, A. J., Navarrete, C. A., Carmody, T., March, D., Hartwell, S. F., Leveno, K. J. (2001). Onset and persistence of postpartum depression in an inner-city maternal health clinic system. Am J Psychiatry, 158(11), pp.1856-63.

[196] Ugarriza D.D. (2000), Postpartum depressed women's explanation of depression, J Nurs Scholarsh, 34 (3), pp. 227-233.

[197] Vieira, T. (2002) When happiness becomes grief: screening tools for postpartum depression. AWHONN,6(6), pp. 506-513.

[198] Waldenström, U. (1999). Experience of Labour and Birth in 1111 Women. J Psychosom Res, 47, pp.471-482.

[199] Waldenström, U., Brown, S., McLachlan, H., Forster, D., Brennecke, S. (2000). Does Team Midwife Care Increase Satisfaction with Antenatal, Intrapartum, and Postpartum Care? A Randomised Controlled Trial. Birth, 27(3), pp.156-167.

[200] Watson, J. P., Elliott, S. A., Rugg, A. J., Brough, D. I. (1984). Psychiatric disorder in pregnancy and the first postnatal year. Br J Psychiatry, 144, pp.453-462.

[201] Webster, J., Pritchard, M. A., Creedy, D. and East, C. (2003) A simplified predictive index for the detection of women with risk for PND, Birth, 30(2), pp.101-8.

[202] Welburn, V. (1980) PND. Manchester University press: Trowbridge and Esher.

[203] Wheatley, S.L., Brugha, T.S., Shapiro, D.A. (2003). PATA PATA: midwives' experiences of facilitating a psychological intervention to identify and treat mild to moderate antenatal and PND. MIDIRS: Midwifery digest 13(4), pp.523-30.

[204] Whiffen, V. and Gotlib, I. H. (1993) Comparison of postpartum and nonpostpartum depression: clinical presentation, psychiatric history and psychosocial functioning, J Consult Clin Psychol, 61(3), pp.485-94.

[205] Whiffen, V. E., Johnson, S. M. (1998). An attachment theory framework for the treatment of childbearing depression.

[206] Wisner, K.L., Parry, B.L., Piontek, C. M.(2002). Postpartum depression.N Engl J Med,347,pp.194-199.

[207] WHO. (1991). Evaluation of methods for the treatment of mental disorders - report of WHO scientific group on the treatment of psychiatric disorders. Geneva: WHO.

[208] WHO. (1992) International Classification of diseases - ICD 10. Geneva: WHO library cataloguing in publication data.

[209] Wisner, K. L., Parry, B, L. and Piontek, C. M. (2002) Clinical practice - postpartum depression, N Engl J Med, 347 (3), pp.194-9.

[210] Wolman, W. L., Chalmers, B., Hofmeyr, G. J. and Nikodem, V. C. (1994a) Postpartum depression and companionship in the clinical birth environment: a randomised controlled trial, Am J Obstet Gynecol, 168(5), pp.1388-93.

[211] Wood, A. F., Thomas, S, P., Drppleman, P. G. and Meighan, M. (1997) The downward spiral of postpartum depression, $M C N$, 22(6), pp.308-16.

[212] Wylie, L., Hollins Martin, C. J., Martin, C. R., Rankin, J. (2011). The enigma of PND: an update. J Psychiatr Ment Health Nurs, 18, pp.48-58.

[213] Zavrl, N. (1999). Očetovanje in otroštvo. Ljubljana: Znanstveno in publicistično središče.

[214] Zlotnick, C., Johnson, S. L., Miller, W., Pearlstein, T. and Howard, M. (2001) "Postpartum depression in women receiving public assistance: pilot study of an interpersonal therapy oriented group intervention", American journal of psychiatry, 158(4),pp. 638-40. 


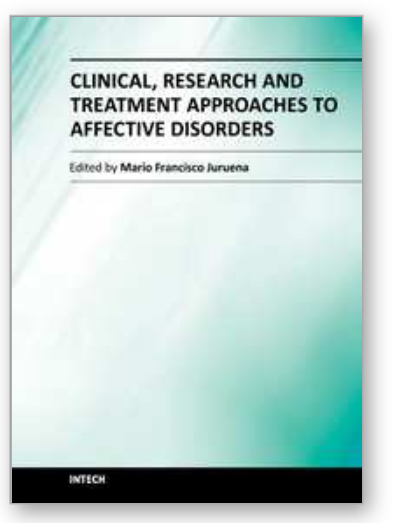

\section{Clinical, Research and Treatment Approaches to Affective Disorders}

Edited by Dr. Mario Juruena

ISBN 978-953-51-0177-2

Hard cover, 364 pages

Publisher InTech

Published online 29, February, 2012

Published in print edition February, 2012

The causes, development and outcomes of disorders are determined by the relationship of psychological, social and cultural factors with biochemistry and physiology. Biochemistry and physiology are not disconnected and different from the rest of our experiences and life events. This system is based on current studies that report that the brain and its cognitive processes show a fantastic synchronization. Written by the foremost experts on Affective Disorders worldwide, this book is characterized by its innovative, refreshing, and highly sensitive perspective on current knowledge of diagnostic, neurobiology, early life stress and treatment of Mood Disorders. The authors share a deep understanding of unique challenges and difficulties involved in Affective Disorders, and have achieved a balance among clinical, research and new treatment approaches to Affective Disorders. The chapters are written in a comprehensive, easily readable, and highly accessible style, stimulating readers, clinicians and researchers.

\section{How to reference}

In order to correctly reference this scholarly work, feel free to copy and paste the following:

Ana Polona Mivšek and Teja Zakšek (2012). Mood Disorders in the Puerperium and the Role of the Midwife: Study on Improvement of Midwives' Knowledge About Post-Natal Depression After an Educational Intervention, Clinical, Research and Treatment Approaches to Affective Disorders, Dr. Mario Juruena (Ed.), ISBN: 978-953-51-0177-2, InTech, Available from: http://www.intechopen.com/books/clinical-research-andtreatment-approaches-to-affective-disorders/mood-disorders-in-the-puerperium-and-the-role-of-the-midwifestudy-on-improvement-of-midwives-knowle

\section{INTECH}

open science | open minds

\section{InTech Europe}

University Campus STeP Ri

Slavka Krautzeka 83/A

51000 Rijeka, Croatia

Phone: +385 (51) 770447

Fax: +385 (51) 686166

www.intechopen.com

\section{InTech China}

Unit 405, Office Block, Hotel Equatorial Shanghai

No.65, Yan An Road (West), Shanghai, 200040, China 中国上海市延安西路65号上海国际贵都大饭店办公楼405单元

Phone: +86-21-62489820

Fax: $+86-21-62489821$ 
(C) 2012 The Author(s). Licensee IntechOpen. This is an open access article distributed under the terms of the Creative Commons Attribution 3.0 License, which permits unrestricted use, distribution, and reproduction in any medium, provided the original work is properly cited. 